\title{
Pumilio is essential for function but not for distribution of the Drosophila abdominal determinant Nanos
}

\author{
Douglas D. Barker, Charlotte Wang, James Moore, Laura K. Dickinson, and Ruth Lehmann
}

Whitehead Institute for Biomedical Research, Howard Hughes Medical Institute and Department of Biology, Massachusetts Institute of Technology, Cambridge, Massachusetts 02142 USA

\begin{abstract}
The Drosophila gene pumilio is expressed maternally, and its function is essential during early embryogenesis for the formation of abdominal segments. Our molecular analysis reveals that pumilio is a large gene that encodes a protein of $160 \mathrm{kD}$ whose RNA is enriched at the posterior pole of the egg. As with pumilio, the maternal effect gene nanos is specifically required for abdomen formation. The Nanos protein is expressed in a posterior-to-anterior concentration gradient in the developing embryo. Previous experiments demonstrated a genetic interaction between pumilio and nanos, and led to the suggestion that pumilio is required for the proper spatial distribution of the Nanos protein. Here, we show that the expression and distribution of nanos RNA and protein in embryos derived from pumilio mutant females are indistinguishable from wild type. We conclude that abdomen formation depends both on Nanos activity, spreading from the localized posterior source, and on Pumilio activity, present throughout the embryo.
\end{abstract}

[Key Words: pumilio; nanos; pattern formation; abdomen formation; translational control; YGL023]

Received July 28, 1992; revised version accepted September 29, 1992.

Specification of cell fate along the anterior-posterior axis of the Drosophila embryo is initiated.by the products of at least 30 maternal genes (Perrimon et al. 1986, 1989; Schüpbach and Wieschaus 1989; C. Nüsslein-Volhard, K. Anderson, G. Jürgens, and R. Lehmann, unpubl.). These maternal genes establish three independently acting signaling systems that subdivide the early embryo into anterior, posterior, and terminal regions (Nüsslein-Volhard et al. 1987; Nüsslein-Volhard 1991; St. Johnston and Nüsslein-Volhard 1992). The anterior and posterior systems act through gradients of morphogenetic proteins emanating from RNA molecules localized to the anterior and posterior poles of the oocyte (Frigerio et al. 1986; Berleth et al. 1988; St. Johnston et al. 1989; Wang and Lehmann 1991). Soon after fertilization, these morphogenetic proteins provide the initial spatial coordinates of the embryo by regulating the expression of the zygotic genome.

The posterior system is responsible for the formation of the segmented abdomen of the embryo (Boswell and Mahowald 1985; Lehmann and Nüsslein-Volhard 1986, 1987, 1991; Schüpbach and Wieschaus 1986; Manseau and Schüpbach 1989; Boswell et al. 1991). Of the 10 genes that constitute the posterior system, the gene nanos plays a central role (Lehmann and Nüsslein-Volhard 1991). The Nanos protein, the posterior determinant, is encoded by a maternal mRNA that is localized to the posterior pole of the oocyte (0\% egg length) (Wang and Lehmann 1991). However, the function of the Nanos protein is required in the presumptive abdomen of the embryo (20-50\% egg length). Nanos specifies abdominal development by repressing translation of maternally derived hunchback mRNA (Tautz et al. 1987; Tautz 1988; Schröder et al. 1988; Hülskamp et al. 1989, 1990; Irish et al. 1989; Struhl 1989). The other known genes of the posterior system share the nanos phenotype as embryos derived from females mutant for any of these genes fail to form abdominal segments. Eight of these genes function before nanos and are required for the posterior localization of nanos RNA (Ephrussi et al. 1991; Lehmann and Nüsslein-Volhard 1991; Wang and Lehmann 1991; L.K. Dickinson, C. Wang, and R. Lehmann, unpubl.). These eight genes also share a second phenotype; embryos derived from mutant females lack the specialized posterior pole plasm that is required for the formation of the pole cells, the germ-line precursors (Boswell and Mahowald 1985; Lehmann and Nüsslein-Volhard 1986; Schüpbach and Wieschaus 1986; Manseau and Schüpbach 1989; Boswell et al. 1991). In contrast, the remaining member of the posterior group, pumilio, has no pole plasm or germ cell defect and is specifically required for abdominal segmentation (this paper, Lehmann and Nüsslein-Volhard 1987).

Previous experiments suggested that pumilio is required to achieve the proper distribution of the Nanos protein within the embryo (Lehmann and Nüsslein-Volhard 1987). Three independent lines of evidence supported this suggestion. First, cytoplasmic transplanta- 
tion experiments implied that the posterior localization of nanos RNA is unaffected by pumilio mutations. The abdominal segmentation defect of most posterior group mutants can be fully rescued by the injection of nanos RNA or the transplantation of wild-type posterior pole plasm, which contains nanos RNA (Lehmann and Nüsslein-Volhard 1991; Wang and Lehmann 1991). Posterior pole plasm from a pumilio mutant embryo contains wild-type levels of this rescuing activity, whereas the posterior pole plasm of nanos mutant embryos, as with all other posterior group mutants, contains no rescuing activity (Lehmann and Nüsslein-Volhard 1987, 1991). This suggests that nanos RNA is properly localized in pumilio mutant embryos and indicates that pumilio must function after the localization of nanos RNA. Second, the abdominal defect of a pumilio mutant embryo can be rescued simply by repositioning pumilio mutant pole plasm to the site of Nanos action, the presumptive abdomen (Lehmann and Nüsslein-Volhard 1987). This means that the functional Nanos protein can be expressed in a pumilio mutant embryo and led to the suggestion that Pumilio affects the transport of the Nanos protein from the pole plasm to the presumptive abdomen. Finally, when a pumilio mutant embryo is injected with pumilio pole plasm, wild-type pole plasm, or in vitro-synthesized nanos RNA, only partial rescue is observed, and this rescue is restricted to the site of injection (Lehmann and Nüsslein-Volhard 1987, 1991; Wang and Lehmann 1991). This observation supported a transport role for Pumilio, as the Nanos protein could not become widely distributed throughout the pumilio mutant embryo.

To understand the role of Pumilio in abdominal development, we have analyzed pumilio mutants and found that pumilio is absolutely required for abdomen formation. To investigate the relationship between pumilio and Nanos, we analyzed the expression of nanos mRNA and protein in pumilio mutant embryos, and demonstrated that pumilio has no effect on the posterior localization of nanos RNA or on the expression or distribution of the Nanos protein. These findings make a transport function for pumilio very unlikely and suggest that Pumilio and Nanos act in conjunction. To address the mechanism of Pumilio function we performed a molecular analysis of the pumilio gene. pumilio is a large gene that encodes an mRNA present in ovaries and early embryos. This RNA is preferentially enriched at the posterior pole of embryos and encodes a $160-\mathrm{kD}$ protein. Near its carboxyl terminus the Pumilio protein contains eight tandemly repeated sequence motifs. A similar sequence of repeated motifs is found in the yeast gene YGL023.

\section{Results}

pumilio is essential for abdomen formation

Previous studies of pumilio suggested that its function was not absolutely required for abdomen formation. Abdominal segmentation could be restored by transplanta- tion of nanos RNA into pumilio mutant embryos or by allowing pumilio mutant embryos to develop at high temperature. This cold-sensitive pumilio phenotype, common to 16 ethylmethanesulfonate (EMS) induced alleles, has been described previously (Lehmann and Nüsslein-Volhard 1987, 1991): Embryos derived from mutant females kept at the restrictive temperature $\left(18^{\circ} \mathrm{C}\right)$ develop very few or no abdominal segments, whereas those kept at the permissive temperature $\left(29^{\circ} \mathrm{C}\right)$ can develop up to the normal number of abdominal segments. Because our molecular analysis (see below) indicated that two chromosomal rearrangements $[\operatorname{In}(3 R) M s c$ and $T(3 ; 1) F C 8$; see Materials and methods] disrupt pumilio, embryos from females carrying these chromosomes would be unlikely to express any intact Pumilio protein. Therefore, we tested the cold sensitivity of these embryos and found them unable to develop abdominal segments at either temperature (see Materials and methods). Thus, the phenotype of this strong pumilio mutant is indistinguishable from that of nanos. In addition, we found that the injection of nanos RNA into embryos derived from $\operatorname{In}(3 R) M s c / T(3 ; 1) F C 8$ females was unable to restore abdominal segmentation (Table 1). This indicates that pumilio function is absolutely required for abdomen formation. Furthermore, it suggests that the EMS-induced $p u$ milio alleles retain partial function and that nanos can only bypass a reduction but not the complete loss of pumilio function.

\section{Pumilio and Nanos affect hunchback protein distribution}

Because nanos and pumilio share the same phenotype, we wondered whether they exert the same effect on hunchback, the target of Nanos function. Nanos functions by repressing the translation of maternally derived hunchback mRNA in the presumptive abdomen (Tautz et al. 1987; Tautz 1988; Schröder et al. 1988; Hülskamp et al. 1989; Irish et al. 1989; Struhl 1989). In doing so, Nanos indirectly regulates the expression of the zygotic gap genes required for abdomen formation, Krüppel, knirps, and giant, which are under the direct control of the Hunchback protein (Hülskamp et al. 1990; Struhl et al. 1992). To determine the effect of pumilio on Hunch-

Table 1. Rescue of abdominal phenotype of nanos and pumilio mutant embryos by nanos transcript

\begin{tabular}{|c|c|c|c|c|c|}
\hline \multirow{2}{*}{$\begin{array}{l}\text { Maternal } \\
\text { genotype of } \\
\text { recipient }^{\mathrm{a}}\end{array}$} & \multirow{2}{*}{$\begin{array}{l}\text { Embryos } \\
\text { injected } \\
\text { (number) }\end{array}$} & \multirow{2}{*}{$\begin{array}{l}\text { Embryos } \\
\text { developed } \\
\text { (number) }\end{array}$} & \multicolumn{3}{|c|}{$\begin{array}{c}\text { Number of abdominal } \\
\text { segments formed } \\
(\% \text { total })\end{array}$} \\
\hline & & & $0-1$ & $2-4$ & $5-8$ \\
\hline \multicolumn{6}{|l|}{$\operatorname{In}(3 R) M S C /$} \\
\hline$T p(3 ; 1) F C 8$ & 220 & 60 & 100 & - & - \\
\hline $\operatorname{nos}^{L 7}$ & 122 & 60 & 3 & - & 97 \\
\hline
\end{tabular}

${ }^{a}$ In vitro-synthesized nanos RNA was injected into the prospective abdominal region of embryos from females of the indicated genotype. 
back, we compared the expression of the Hunchback protein in wild-type and pumilio mutant embryos. In cleavage-stage embryos, expression of the Hunchback protein is derived from a uniformly distributed maternal hunchback mRNA (Tautz et al. 1987; Tautz and Pfeifle 1989). In wild-type embryos (Fig. 1) translation of the maternal Hunchback protein from this RNA is restricted to the anterior half of the embryo (Tautz 1988; Tautz and Pfeifle 1989|. In embryos from females mutant for EMSinduced pumilio alleles, the domain of Hunchback protein expression expands in the posterior direction (Fig. 1; see also Tautz 1988); whereas in strong pumilio mutant embryos, the Hunchback protein is expressed at high levels throughout the embryo (Fig. 1). Thus, Pumilio affects hunchback translation to the same extent as Nanos does (Tautz 1988; Wharton and Struhl 1991).

\section{Distribution of the Nanos protein is unaffected by pumilio}

The similarity between the nanos and pumilio phenotypes precludes the ordering of these two genes in a ge-

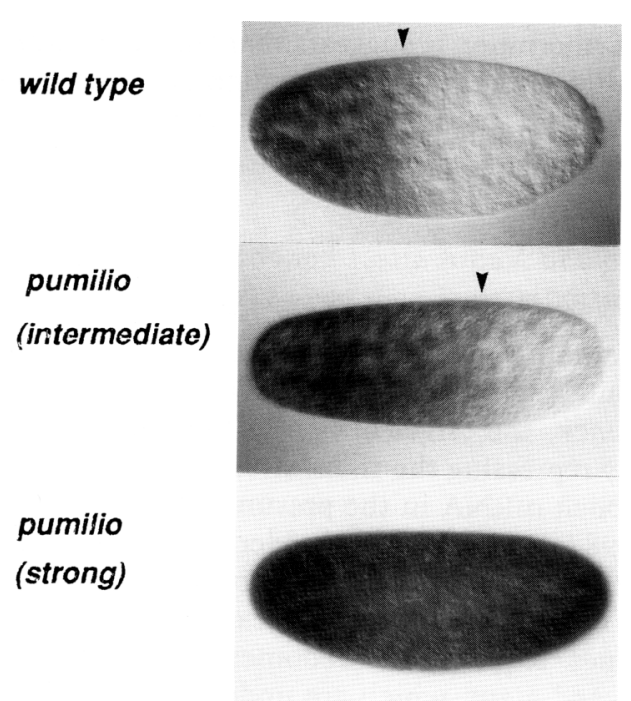

Figure 1. pumilio affects hunchback translation. Maternal genotypes of the embryos shown are indicated at left. (Top) The shallow gradient of the Hunchback protein expressed from the maternal mRNA in a wild-type embryo. The Hunchback protein gradient is expanded posteriorly in an embryo derived from a female mutant for pumilio alleles of intermediate strength $\left(\mathrm{pum}^{680} /\right.$ pum $^{E T 1}$, kept at the restrictive temperature, $20^{\circ} \mathrm{C}$, middle). The expansion of Hunchback is indicated by arrowheads. In embryos from females transheterozygous for breakpoint mutations in the pumilio gene [strongest phenotype, In(3R)Msc and $T(3 ; 1) F C 8$ ], hunchback is translated uniformly throughout the embryo (bottom). This expression of the Hunchback protein is identical to the distribution found in embryos from nanos mutant females (Tautz 1988). In some experiments we noticed a high staining intensity throughout pumilio mutant embryos that exceeded that observed in wild-type embryos at the anterior pole. The embryos shown are in nuclear cycle eight or nine (Foe and Alberts 1983). For all embryos, anterior is left and dorsal is up. Nomarski optics were used.
Table 2. Rescue of abdominal phenotype of nanos mutant embryos by posterior pole plasm

\begin{tabular}{llllll}
\hline $\begin{array}{l}\text { Maternal } \\
\text { genotype } \\
\text { of donor }\end{array}$ & $\begin{array}{l}\text { Embryos } \\
\text { injected } \\
\text { (number) }\end{array}$ & $\begin{array}{l}\text { Embryos } \\
\text { developed } \\
\text { (number) }\end{array}$ & $\begin{array}{l}\text { Number of abdominal } \\
\text { segments formed } \\
\text { (\% total) }\end{array}$ \\
\hline In(3R)MSC/ & & & & $2-4$ & $5-8$ \\
Tp(3;1)FC8 & 35 & 17 & 58 & 18 & 24 \\
Wild type & 58 & 20 & 50 & 35 & 15 \\
\hline
\end{tabular}

aposterior pole plasm of embryos derived from females of the indicated genotype was injected into the prospective abdominal region of embryos from nos ${ }^{L 7}$ females.

netic pathway. To identify interactions between these two genes, we determined whether pumilio mutations interfere with the synthesis, distribution, or stability of nanos RNA and protein. In wild-type embryos nanos mRNA is localized to the posterior pole plasm (Wang and Lehmann 1991). Transplantation of this cytoplasm into the presumptive abdomen of a nanos mutant embryo is sufficient to restore abdominal segmentation. Similarly, pole plasm derived from a pumilio mutant embryo is equally able to induce abdominal segmentation, suggesting that the localization of nanos mRNA is unaffected by the pumilio mutation (Table 2; Lehmann and Nüsslein-Volhard 1987, 1991). To investigate this at the molecular level, we performed in situ hybridization to whole-mount embryos and confirmed that the localization of nanos RNA in pumilio mutant embryos appears normal (Fig. 2A,B). Thus, Pumilio function is not required for nanos RNA synthesis or localization. This suggests that Pumilio interacts with the Nanos protein.

Pumilio might control Nanos protein activity in the presumptive abdomen and could do so by a number of different mechanisms. Because the abdomen is derived from a region of the embryo that is anterior of the pole plasm, Pumilio could be required to transport the Nanos protein from the posterior pole toward the prospective abdomen as suggested initially (Lehmann and NüssleinVolhard 1987). Alternatively, Pumilio might control nanos translation or Nanos protein stability. Furthermore, Pumilio could be required for Nanos protein function without changing its concentration or distribution.

To distinguish among these possibilities, we compared the expression and distribution of the Nanos protein in wild-type and pumilio mutant embryos using an antiNanos antiserum. The Nanos protein forms a concentration gradient emanating from the posterior pole and extending into the presumptive abdomen. Our initial observations on large numbers of whole-mount embryos indicated that the expression of the Nanos protein is very similar in wild-type and pumilio embryos (Fig. 2C,D). This indicates that Pumilio is not necessary for the synthesis or stability of the Nanos protein. To determine the relative distribution of the Nanos protein more objectively, we used a modification of the filtered fluorescence-imaging technique (Karr and Kornberg 1989), 


\section{nanos RNA}

A

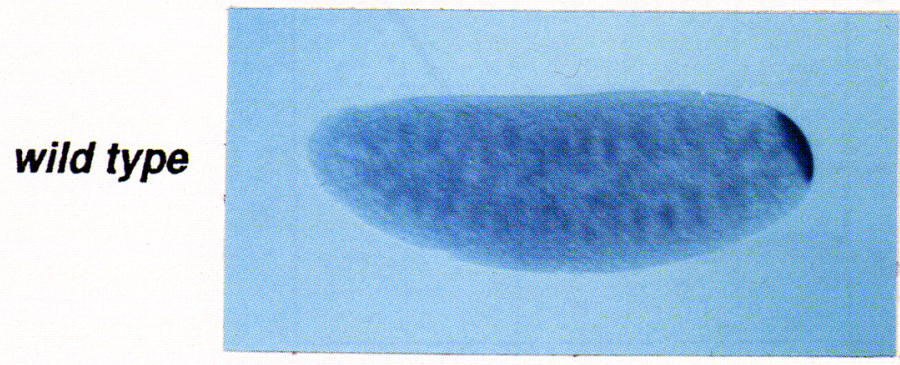

B

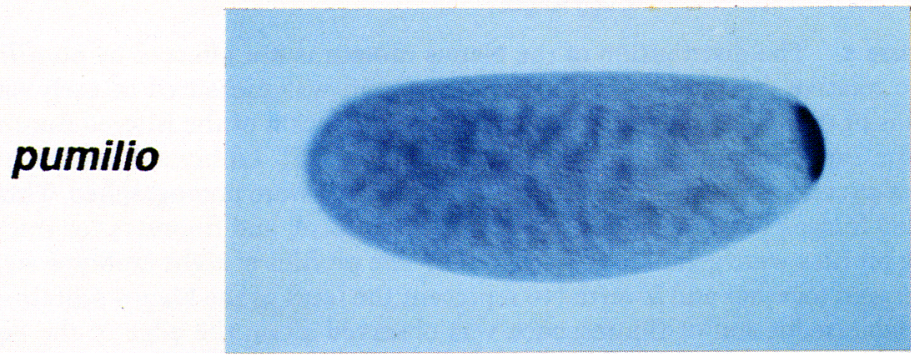

\section{NANOS protein}

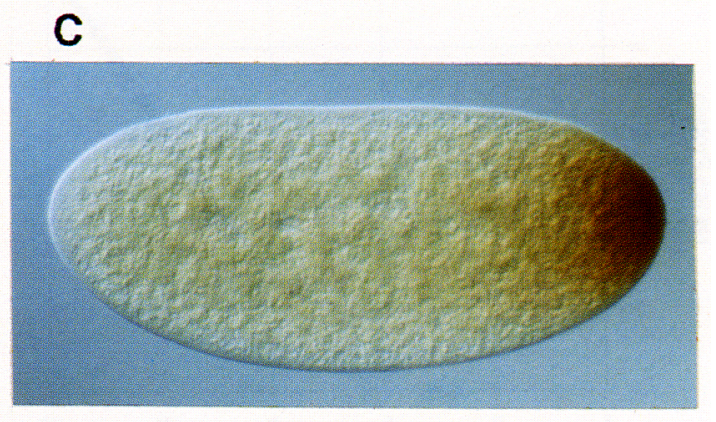

D

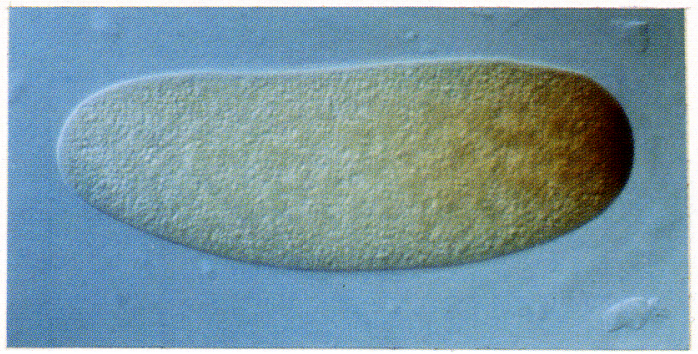

Figure 2. pumilio has no effect on the expression of nanos RNA and the Nanos protein. The localization of nanos RNA in embryos derived from wild-type $(A)$ and pumilio $(B)$ females is indistinguishable. Similarly, the distribution of the Nanos protein in wild-type $(C)$ and pumilio $(D)$ embryos appears identical. Antibody staining was performed with a rabbit polyclonal anti-Nanos serum. Identical results were observed with embryos from females mutant for pumilio ${ }^{680}$ (at the restrictive temperature $20^{\circ} \mathrm{C}$ ) and embryos from females transheterozygous for $\operatorname{In}(3 R) M s c$ and $T(3 ; 1) F C 8$ (data not shown). The embryos shown are in nuclear cycle seven or eight (Foe and Alberts 1983). For all embryos, anterior is left and dorsal is up. Nomarski optics were used.

which combines the enhanced sensitivity of enzymelinked immunohistochemistry with the high contrast of fluorescence microscopy. The data obtained using this technique demonstrate that the relative distribution of the Nanos protein in wild-type and pumilio embryos (Fig. $3 \mathrm{~A}$ ) is indistinguishable.

To confirm that this technique is capable of measuring differences in the relative distribution of the Nanos protein sufficient to account for the pumilio phenotype, we compared the distribution of the Nanos protein in embryos derived from females carrying either one copy or four copies of the nanos gene (Fig. 3B). This difference in nanos gene dosage has no detectable effect in an otherwise wild-type background. However, in embryos from females mutant for an EMS-induced pumilio allele, which express partial pumilio function, this difference in nanos gene dosage is sufficient to induce the formation of three abdominal segments (Fig. 3C). Embryos derived from females carrying one copy of nanos ${ }^{+}$form $\sim 0.6$ abdominal segments, whereas embryos derived from females carrying two or four copies of nanos form $\sim 1.7$ and 3.4 abdominal segments, respectively. When the distribution of the Nanos protein was measured in these embryos, a small but significant difference was observed (Fig. 3B). Thus, we are able to detect a difference in the relative distribution of the Nanos protein that is sufficient to produce a three-segment difference in pheno- type. Therefore, our failure to detect a difference between wild-type and pumilio embryos, which differ by eight abdominal segments, means that the pumilio phenotype cannot be the result of an altered distribution of the Nanos protein. This result indicates that pumilio is not required for either the expression of the Nanos protein or its transport to the presumptive abdomen.

\section{Molecular identification of pumilio}

To address further the mechanism of Pumilio function we have isolated the pumilio gene and performed a molecular analysis. The cytological position of pumilio has been determined by deficiency mapping to position 85CD of the polytene chromosome (Lehmann 1985; Lehmann and Nüsslein-Volhard 1987). To isolate pumilio sequences we took advantage of the observation that the inversion, $\operatorname{In}(3 R) M s c$, fails to complement pumilio (Lehmann 1985) and that the proximal breakpoint of In(3R)Msc at 84A lies within the Antennapedia complex (Scott et al. 1983; T. Kaufman, pers. comm.). A bacteriophage clone from the Antp region (gift of $\mathrm{M}$. Scott) was used to isolate fragments spanning the $\operatorname{In}(3 R) M s c$ breakpoints. Sequences from the distal breakpoint at $85 \mathrm{CD}$ were used to begin a genomic walk in a wild-type cosmid library (Fig. 4A).

An embryonic cDNA library (gift of N. Brown; Brown 


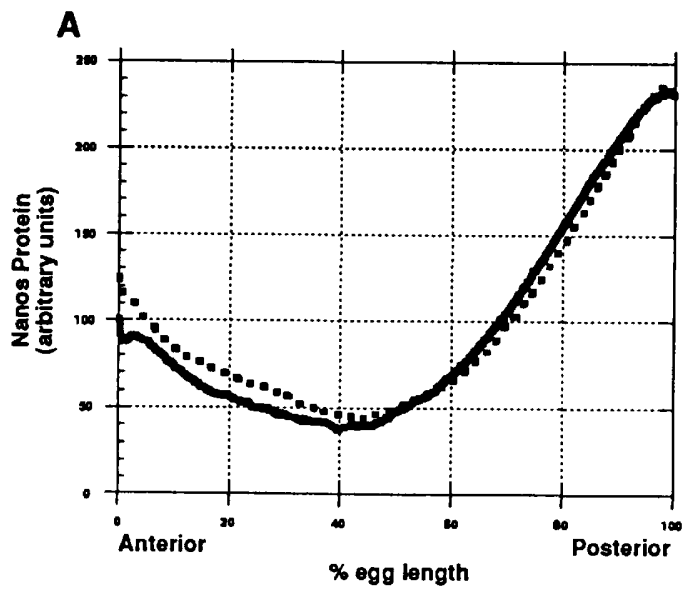

C

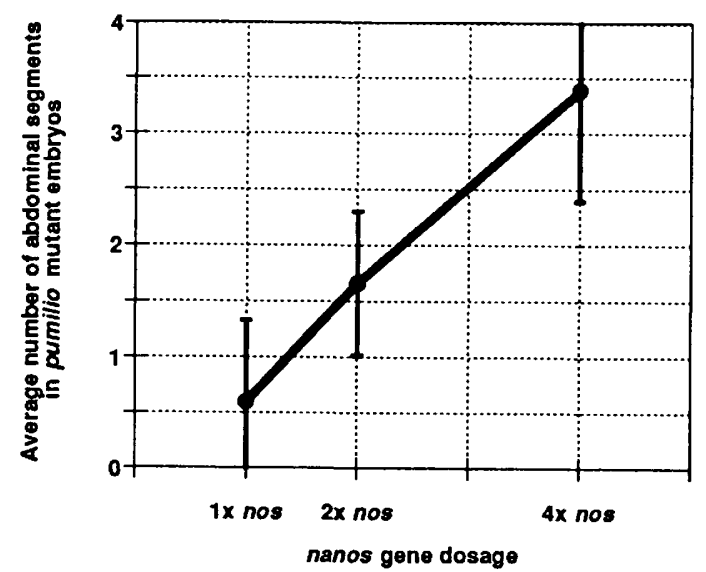

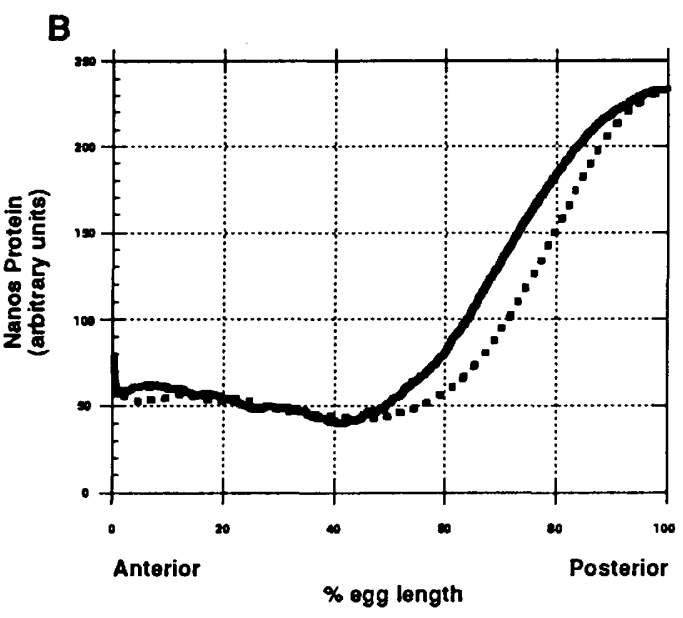

Figure 3. The distribution of the Nanos protein is not affected by pumilio. The relative distribution of the Nanos protein was measured in early embryos of the indicated genotypes using a modification of the filtered fluorescence imaging technique (Karr and Kornberg 1983). Embryos between nuclear cycles seven and nine (Foe and Alberts 1983) were photographed. These video images were then converted into digital form, and fluorescence intensity profiles were generated by computer. The profiles of eight embryos were averaged together and inverted to represent the level of the Nanos protein. A variable reduction of fluorescence was observed along the edge of the embryos independent of the Nanos antibody. $(A)$ There is no significant difference in the distribution of the Nanos protein between wild-type (solid line) and pumilio (broken line) mutant embryos, whereas a statistically significant difference can be observed between embryos carrying one copy (Df(3R);DIFX1/TM3; broken line) or four copies (P/gnos]/P/gnos]; solid line) of the nanos gene $(B) .(C)$ The effect of varying the nanos gene dosage on the phenotype of pumilio embryos mutant for EMS-induced alleles. The data were obtained by preparing cuticles and determining the average number of abdominal segments formed after embryogenesis at $20^{\circ} \mathrm{C}$ (restrictive temperature). These embryos were produced by females of the following genotypes: $1 \times$ nanos $^{+}$, pum $^{E T 3} / p^{2 u m}{ }^{680}$, nos $^{L 7} ; 2 \times$ nanos, $\mathrm{pum}^{E T 3} /$ pum $^{680} ; 4 \times$ nanos $^{+}{ }^{\text {pum }}{ }^{E T 3} /$ pum $^{680} ;$ P/gnos $\left./ / P / g n o s\right]$. The mean numbers of abdominal segments, $1 \times$ nos, $0.6 ; 2 \times$ nos, $1.7 ; 4 \times$ nos, 3.4 , were calculated from sample sizes of 308,160 , and 235 embryos, respectively. The error bars indicate the standard deviation of these samples.

and Kafatos 1988) was screened with two genomic fragments from the distal breakpoint of the Msc inversion, and a group of related cDNAs was identified by hybridization to both probes. The largest of these, clone R7-1, was used to probe a blot containing mRNA isolated from different developmental stages (Fig. 4B). This clone hybridizes to an RNA molecule $6.5-7 \mathrm{~kb}$ in length that is present in ovaries and early embryos, a pattern consistent with the maternal requirement for pumilio function. In addition, a larger mRNA producing a weaker signal was also detected during the same stages. We determined that this cDNA clone was derived from $p u$ milio by analyzing wild-type and mutant polytene chromosomes by in situ hybridization. cDNA R7-1 hybridizes to the position of pumilio $(85 \mathrm{CD})$, and this hybridization signal is interrupted by the two breakpoints known to disrupt pumilio function, $\operatorname{In}(3 R) M s c$ and $T(3 ; 1) F C 8$ (data not shown; Lehmann 1985).

When fragments of this pumilio cDNA were hybridized to the cloned genomic DNA, it became apparent that the 3 ' end of the pumilio transcription unit extends beyond the limits of the initial genomic walk (Fig. 4). Using R7-1 cDNA sequences as probes, cosmid clones spanning the entire pumilio gene were isolated, except for one region that is apparently not represented in the libraries we screened.

\section{Structure of pumilio and its products}

The nucleotide sequence of pumilio was determined by sequencing both strands of the cDNA R7-1 and portions of other cDNAs and has been confirmed by sequencing the corresponding genomic regions (Fig. 5). pumilio encodes two mRNAs that contain different $5^{\prime}$ exons and are both present in early embryos. Each mRNA contains 13 exons spanning $\geqslant 160 \mathrm{~kb}$ of the genome, including a single intron covering $\geqslant 120 \mathrm{~kb}$ (see Fig. 4A). We have obtained 6835 nucleotides of cDNA sequence corresponding to one RNA and 6674 nucleotides for the other; both encode an identical open reading frame. The $5^{\prime}$ untranslated regions contain multiple stop codons, indicating that this sequence contains the entire protein-coding 


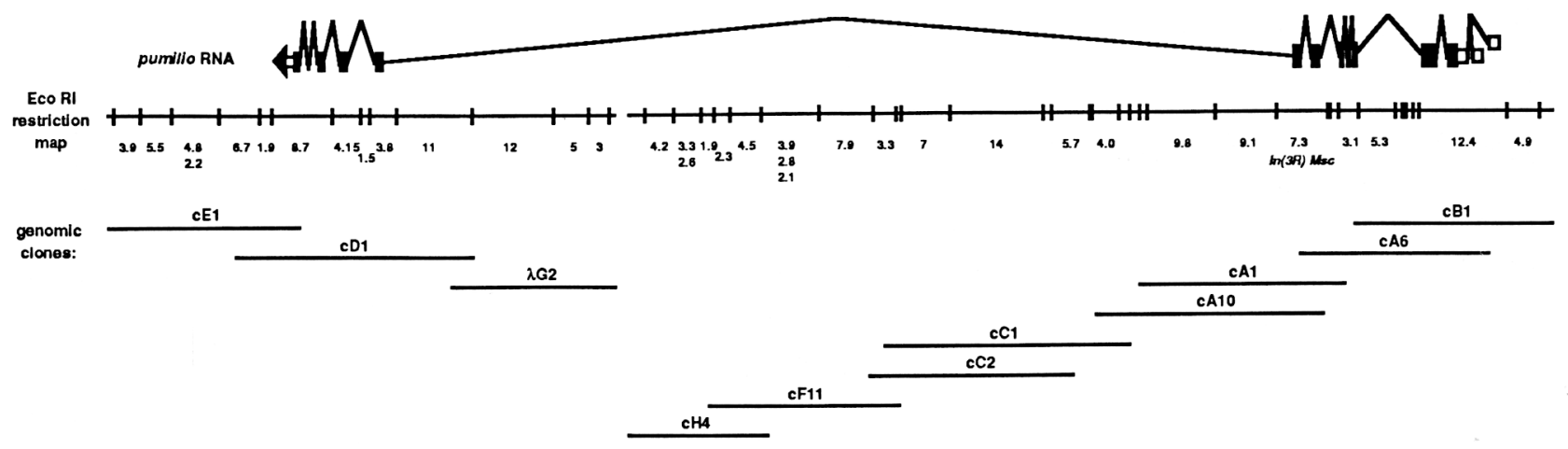

B

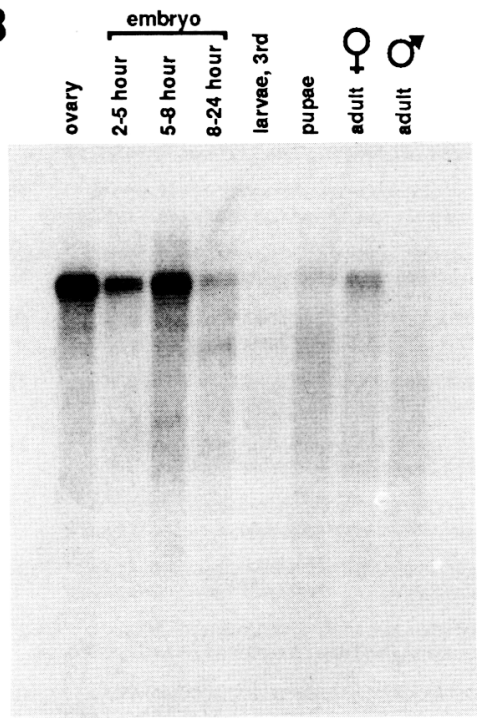

Figure 4. Structure and expression of pumilio. $(A)$ The intron-exon structure of the pumilio gene is indicated above an EcoRI restriction map of the region. Transcription proceeds from the right in a distal-to-proximal direction on chromosome 3 . The exons are positioned above the restriction fragments from which they are derived but are not drawn to the same scale. The position of the $\operatorname{In}(3 R) M s c$ breakpoint used to clone this region is indicated. The location of this breakpoint indicates that this mutant could express no more than a severely truncated protein. In addition, a breakpoint of the translocation $T(3 ; 1) F C 8$ falls within the pumilio gene; however, its location has not been identified. Also contained within these sequences is the gene for the chromosomal protein D1, which had been mapped previously to this region of the third chromosome (Ashley et al. 1989). Chromosomal protein D1 sequences have been identified in the distal (right) region of cosmid cB1. Below the EcoRI restriction map, the position of genomic cosmid and bacteriophage $\lambda$ clones are indicated. $(B)$ The developmental expression of pumilio RNA was analyzed with an RNA blot. Polyadenylated RNA ( $2 \mu \mathrm{g})$ isolated from the developmental stages indicated were fractionated on a formaldehyde-agarose gel and transferred to a nylon membrane. This blot was then hybridized with a probe derived from the R7-1 CDNA that had been uniformly labeled with ${ }^{32} \mathrm{P}$. Hybridization with other probes, including bicoid and genomic clones that reveal chromosomal protein D1 transcripts, indicates that the apparent increase in pumilio expression at $5-8 \mathrm{hr}$ is the result of overloading relative to other lanes. region. Downstream of the open reading frame is a relatively large 3'-untranslated region of 1193 nucleotides. A portion of the pumilio sequence has also been reported by Macdonald (1992). The pumilio open reading frame encodes a protein with a predicted molecular mass of 160 $\mathrm{kD}$. Its amino acid sequence indicates that it is a novel protein. One region of this protein, however, near the carboxyl terminus (amino acids 1111-1401) contains a repeated sequence motif (Macdonald 1992). This sequence can be aligned to reveal the presence of eight repeated units (Fig. 5B). Specific amino acids are conserved at a few positions; however, a more extensive conservation of the chemical nature of amino acids is observed throughout this region (Fig. 5B).

This region of the Pumilio protein is strikingly similar to a portion of the open reading frame encoded by the Saccharomyces cerevisiae gene YGLO23 (Chen et al. 1991). This 888-amino-acid protein of unknown function contains a sequence near its carboxyl terminus that can also be aligned into eight repeated units that are similar to those of pumilio (Fig. 5B). Comparison of specific Pumilio repeats to the corresponding Ygl023 repeats re- veals additional similarities that indicate the presence of a further pattern appearing every two repeats. In addition, the positions of a number of other amino acids are conserved in specific repeats, which indicates that the different repeats may be functionally distinct and that the order of the repeats is conserved.

\section{A pumilio minigene complements the pumilio mutant phenotype}

The large size of pumilio makes it impossible to use P-element-mediated transformation to identify all of the genomic sequences required for pumilio function. Therefore, to demonstrate that the R7-1 cDNA encodes the functional Pumilio protein, we introduced a pumilio minigene containing the $\mathrm{R} 7-1$ open reading frame into the germ line of pumilio mutant flies and tested its ability to complement the pumilio mutant phenotype. To direct transcription of the cDNA, we used the oogenesisspecific nanos promoter (Gavis and Lehmann 1992), because we expected the temporal regulation of its expression to be appropriate for pumilio. The resulting nanos- 
A

СTCTCCTCTCTCTCTAGCTCTPTGTTGTAGTTGTATTTGGCCAGTGTGTCTTTGCATTTCGCTTTTATTATCGTTCTGCGACGGACGGCGGCGACGTTGAAGAAATTCCTGGCCGATTTC ACACTAAATGTTCGCGCGTAAGAAGAAGCAGACCTAGAACGGCGTGCTTGTAATATGTAAATTTTTTCAAATAAGCTAAG TTCTTCATCATCCTGTGTAAATAATTGTAATTTAAATAATCTAAATTTCGTATTTAACGAAAGCACACACACCATCAAATCAATGGAAATGCAAACGAGAAGGCTTPTTTTAAGTGCATGT $\underset{G}{\operatorname{T}}$ exon 2 GT TCAAGTTTTAACCAATTCTCATACGTAATTAAATAAATAAAGTTCAGTTTTGTTAAGTCCCAAAAACAACAGCTGTGCAACTGTGTAAAATATTATTCATAATTTTGTGTAAATTTATGT AAAAAAAAAAAAAAAAACAAACCAACCACGACAACCAAACCAAACGAAGCAAATTCAATTTTTTTGATCAAAAAGTGTGTGAAAAATCTCAGCAAAGCCTGTAAAATAAATATTAAATAT ATTAAGCAAAAAGTGTGGTTTCTTTTACAACAAAATAAATAAAAGCAAAAAACAAGTGTAAATCTGAAGCGAAAATTAAAAAAAAATTATATGTAACATTTGTGAATATPTCCGAGCGAA TAGTGTTGCAAAACGCGCGTGTGGTTCTTTGTGCTGCAAGTTAAAATACAATTCAAGTTGGCAATACGCGCAAAATTGTCAGCTGCGATAGCTAGGAAAAGCCTCCAAAATTGAGCTCCT AACCGCGCCCACAATTGCCATATCGACGCCCTCGCCGCAGCAGCAACACCAACAGCAGCAGCAGCAGCAGCAGCAGCAACTCTATCAGCAACATCAACAGCAGCAGCAGCAACATTACGG TCCACCACCGCCCTACTTTCAACAGCTACACCAGCAACACCAACAGCAGCAGCAACAACAGCAGCAGCAGCAACACCAGCAACACATGAAGTTTTTGGGTGGTAACGATGATCGCAATGG CCGCGGAGGCGTCGGCGTTGGCACGGATGCCATTGTAGGATCTCGAGGTGGCGTCTCTCAGGATGCCGCCGATGCAGCTGGTGCCGCCGCAGCCGCCGCCGTCGGCTATGTCTTCCAGCA

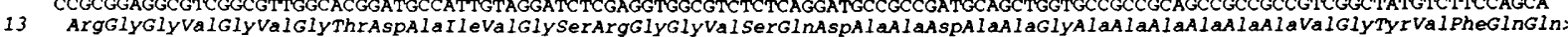
GCGTCCATCGCCTGGTGGGGTTGGCGTCGGCGTGGGCGGAGTGGGTGGCGGTGTGCCAGGGGTCGGAGCCGTAGGCTCAACCTTGCACGAGGCCGCCGCCGCCGAGTACGCCGCCCACTT TGCCCAGAAGCAACAGCAGACCCGATGGGCGTGCGGCGACGACGGCCATGGGATCGATAACCCGGACAAA

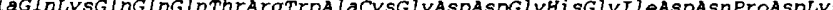

ACCGGGAAATGGCAGTAATGGTGGGCCCGGCGCCATTGGAACCATTGGCATGGGCAGCGGATTGGGTGGTGGTGGCGGCGGCGGAGCTGGCGGCGGAAATAATGGCGGCTCTGGTACGAA

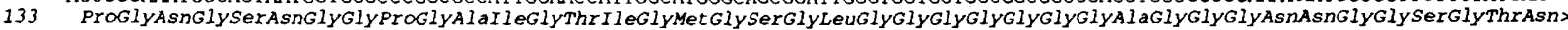
TGGCGGTCTGCATCATCAATCGATGGCCGCTGCAGCTGCGAATATGGCAGCCATGCAACAGGCGGCGGCGTGGCCAAGCACAATCACATGATATCACAGGCAGCAGCCGCAGTTGCAGC

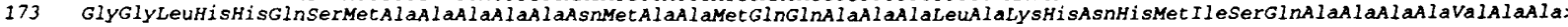
CCAGCAACAACATCAGCATCCACACCAGCAGCATCCCCAGCAGCAGCAGCAACAGCAGCAGGCGCAGAACCAGGGGCATCCACATCACCTTATGGGCGGTGCAATGGACTGGGCAACGG

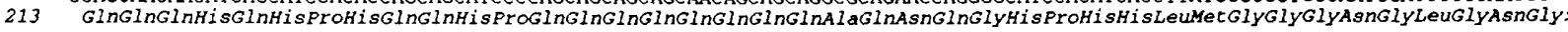
CAATGGATTGGGCATACAACATCCCGGCCAGCAACAGCAGCAGCAGCAGCAACAACAGCAGCAGCAACATCCCGGCCAGTACAACGCGAATCTGCTTAACCATGCGGCTGCCTTGGGTCA

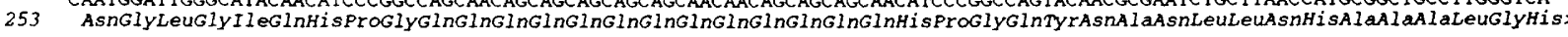
CATGTCATCTTATGCCCAATCGGGTGGCAGCATGTACGACCATCATGGTGGAGCCATGCACCCGGGAATGAACGGCGGCATGCCCAAGCAACAGCCATTGGGTCCACCCGGAGCCGGAGG

293 MetSerSerTyralaGlnSerGlyGlySerMet TyrAspHisHisGlyGlyAlaMet HisProGlyMetAsnGlyGlyMetProLysGlnGInProLeuGlyProProGlyAlaGlyGIy> ACCCCAGGACTATGTCTACATGGGTGGCCAGACCACTGTGCCCATGGGAGCCGCAATGATGCCGCCACAGAATCAATATATGAACAGCTCTGCTGTTGCAGCTGCCAATCGGAATGCAGC 3

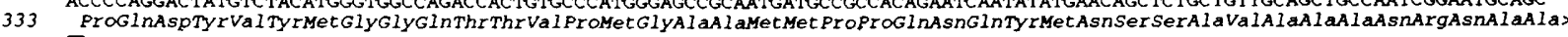
$\nabla$ exon 4

373 GATACTCATC

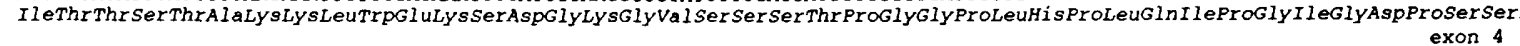
CGTGTGGAAGGATCACACCTGGTCCACACAGGGCGAGAATATATTGGTGCCGCCCCCCTCGCGAGCCTACGCCCATGGAGGCGCCTCCGATACTTCAAACAGCGGCAATGCGGGCATACT

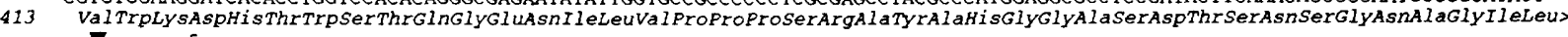
7 exon 5

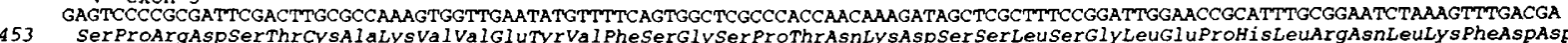

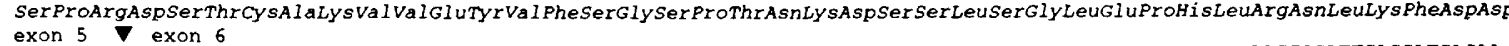
CAACGATAAGTCACGCGACGATAAGGAGAAAGCAAACTCTCCGTTTGACACAAACGGTTGAAGAAAGACGATCAGGTCACAAACTCAAATGGTGTTGTCAACGGCATTGACGATGACAA

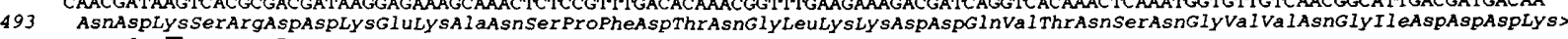
exon 6 exon 7

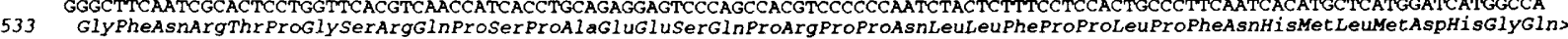
AGGCATGGGAGGCGGCTTGGCGGAGTTGTTGGATCTGGCAACGGAGTCGGCGGTGGCAGCGGCGGAGGCGGGGCAGGCGGCGCTTATGCGGCCCACCAGCAGATGGCCGCCCAGATGAG

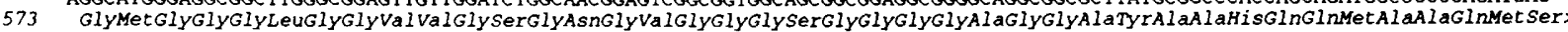
TCAATTGCAACCGCCGATCATGAACGGCGTTGGCGCCGGAATGCCAT exon 7 exon 8

TCACCAGGCAGCTGGACCCAATCATATGGAATCTCCCGGAAATCTCTT CroMetLeUASnHISGInAlaAlaGlyProAsnHisMetGluSerProGlyAsnLEULEU GCAGCAGCAAAATTTTGATGTTCAGCAACTGTTTCGCTCGCAGATCCGGGCCTAGCAGCAGTTGCCACAAATGCAGCGGCCGCAGCAGCAGCCGCAGCAGCTGCCACATCGGCAGCGAG

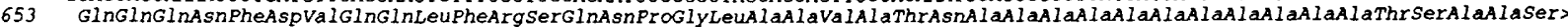
TGCTGCGGCAGCGGTGGGCGCACCACCCGTTCCCAACGGATCGCTGCAGCAGTCGCAGCAGCAACAGCAGCAGCAGCAACAACAGCAGCAGCAACAACAGATGCACATGGCGGCCGCGTC

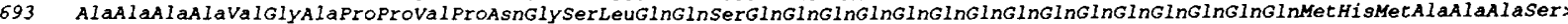

GCAACAATTTTTGGCCGCCCAGCAGCAGGCGCAAAATGCGGCCTATGCCGCCCAACAGGCCACGTCCTACGTCATCAATCCGGGCCAGGAGGCTGCCCCGTATATGGGCATGATTGCCGC

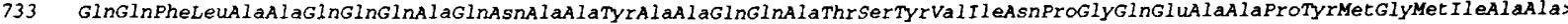

CGCCCAGATGCCGTACTATGGCGTAGCACCATGGGGCATGTATCCGGGCAATCTGATTCCGCAACAGGGAACGCAGCCGCGCCGCCCCCTCACCCCCTCGCAGCAGGGTGCCGAGAATCA

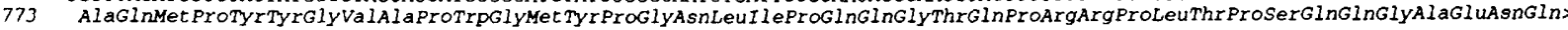
GCCGTATCAGGTCATCCCGGCATTCCTCGATCACACGGGCTCCTTGCTGATGGGAGGACCTCGCACCGGGACGCCGATGCGTCTGGTTAGCCCCGCCCCCGTTCTGGTGCCCCCGGGCGC

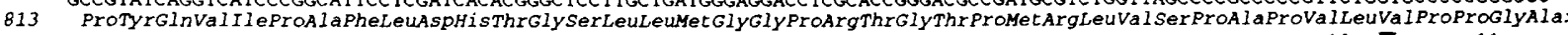
TACCCGTGCCGGCCCCCCGCCCCCGCAGGGGCCACAGCTGTATCAGCCGCAGCCGCAGACGGCCCAACAGAATCTCTACTCGCAGCAGATGGATCCAGTGTCGGAGGCCTCGCCTTGAA 110

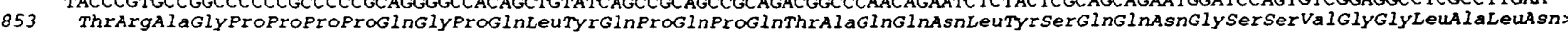
CACGAGCTCGTTGACGGGTCGCCGCGACTCCTTCGACCGCAGCACCTCCGCCTTCAGTCCCTCGACCATGGACTACACCAGCAGCGGTGTGGCAGCGGCCGCCAATGCGGTGAACAGCAC

893 ThrSerSerLeuThrGlyArgArgAspSerPheAspargSerThrSerAlaPheSerProSerThrMetAspTyrThrSerSerGlyValAlaAlaAlaAlaAsnAlaValAsnSerThr AGTGGCCCAGGCAGCAGCAGCTGCCGCAGCAGCCGCCGCAGCGCGTGGCAAGTGGCCGGGAGCGATGTCGGGAGCGGCCAGTGGAGCCTACGGAGCCCTGGGAGCGGGCAATGCTTCGGC

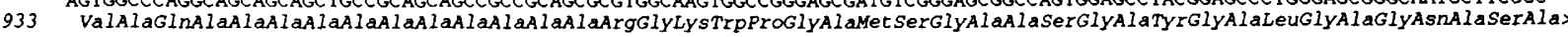
CAGTCCCCTGGGCGCACCAATCACGCCGCCGCCATCGGCGCAATCCTGTCTCCTGGGCAGTCGGGCACCTGGAGCCGAGTCCCGCCAGCGGCAGCAGCAACAACAGCAGCTGGCCGCCGT

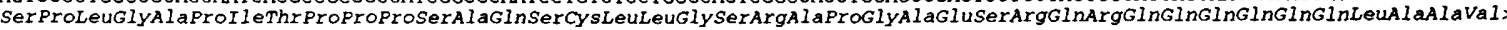
TGGTCTGCCGGCGACTGCAGCAGCTGCTCAGGCAGCGGTGGCCGCGGCTGCCAACAATATGTTCGGATCCAACAGCTCGATCTTCTCGAATCCCCTGGCCATTCCGGGTACCGCAGCTGT

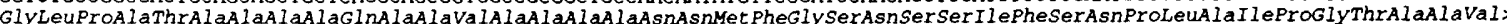
GGCAGCTGCAGCGGCAGCAGCAGCGGCCGCCAACTCGCGTCAGGTGGCTGCCACGGCAGCGGCAGCAGCGGCGGTGGCAGCAGCAGCCGGCGGAGTGGGAGGTGCCCCACAGCCAGGAAG

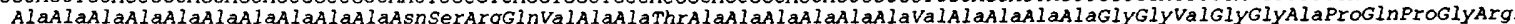
ATCTCGCCTTCTCGAAGATTTCCGCAACCAGCCGTATCCAAATCTTCAGCTACGCGATCTCGCTAACCACATTGTGGAGTTCTCACAGGATCAGCACGGCTCGCGGTTTATCCAACAGAA

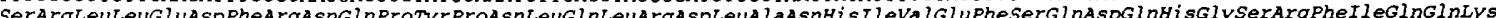
GTTGGAGCGGGCCACCGCCGCCGAGAAGCAAATGGTGTTCAGCGAGATCCTGGCGGCAGCCTATAGCCTGATGACCGATGTCTTTGGCAACTATGTCATCCAGAAGTTCTTTGAGTTCGG

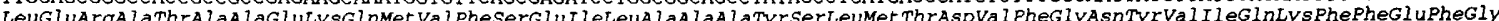

Figure 5. (See facing page for legend.) 

TCTGGTGCTATCACAGCACAAGTTCGCCTCAAACGTTGTGGAGAAATGTGTTACCCATGCCACTCGCGGAGACGCACTGGTCTCATAGACGAGGTCTGCACCTTCAACGACAACGCGTT

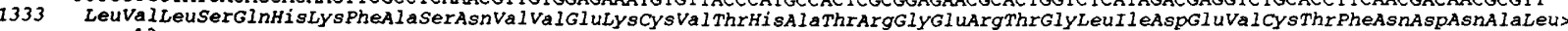
exon 13

GCACGTGATGATGAAGGATCAGTATGCCAACTATGTGGTCCAAAAAATGATCGATGTATCGGAGCCGACGCAGCTCAAGAAGCTGATGACCAAGATCCGGCCCCACATGGCCGCCTTGCG

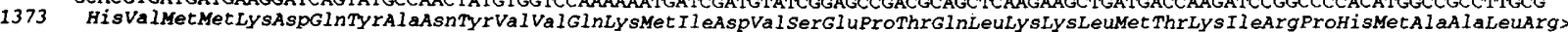

CAAGTACACCTACGGCAAGCACATCAATGCCAAGTTGGAGAAGTACTACATGAAGATAACCAATCCCATTACGGTGGGCACAGGAGCTGGAGGAGTGCCGGCAGCCTCGTCGGCGGCCGC

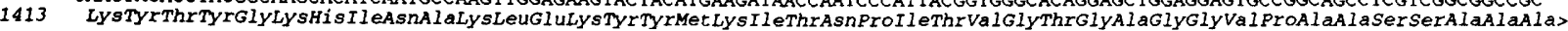
GGTCAGCAGTGGTGCCACCTCGGCATCGGTAACCGCCTGCACCAGTGGCAGCAGCACCACCACGACCAGCACTACCAACAGCCTGGCCTCACCCACCATTTGTTCGGTGCAGGAGAACGG 1453 ValserSerGlyAlaThrSerAlaserValThrAlaCysThrSerGlySerSerThrThrThrThrSerThrThrAsnSerLeuAlaSerProThrTleCYsSerValGlnGIuAsnGly> CAGCGCCATGATTGTGGAGCCCTCCTCCCCGGACGCCTCCGAGTCCTCGTCCTCGGTGGTGTCAGGCGCTGTCAACAGCGGCTTGGGTCCCATTGGACCCCCGACCAACGGCAACGTTGT

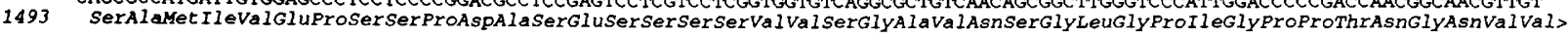
GCTGTAAAGGAATAACAAATTAAGCCAGGCAGTCAAAGGAACTTCCTTCTCGAATCGCAGTATAGTTTTTAGAAGCTGTAGAGCTTAACATAAACAACAAGTACATATAAATGTAATC

TTATTTATTGGAAAAGAGCGATAAATGGAGCTGCACTCGAAGATTTGCAAAGAGGATAGTAAAACACACATGCGCCAATCTAGAGAAACAAAGCAAACAAAGAAGCACACTGGCAAGCC AAAAAGCAAAAGAGCTTAACAGCTAAAACTAAAAGAAATTTGTATTTTTACGAACAAAACTAATAACGTTCTCATGAAAAAAGATTTCAAAATATTTGTAAAATGCGATCGCATAATTAA TTTGTAAAAAAAAGGCATGAACCGCAAAGATGAAAGAAAACAAAAATGCGTAGTTAATCTCGATCAAGAAAAAATAATGAATGTAATGTAAAATGTCAATGAAACAGATTTGTCTGCGT CATTTTCGTTGTAACTITGTATAAATTAATTATTATATAGCAAGTCTATCTGTAAAGGATTAATGTTTCGACTGTAAATTAATAAGAAGACAACTGAAGAGCCGGCGAGCTGAAAAAAAA GAAAGTAAAAAGAGCGGGCTGCATGAATTAGCCTACGATTTATAAGTTCAGACAGAGGACCATTTCTAATATACAAACATATATACGAGGGATAACAGCAGAAGCCGCACTTAGTGTAG AATGTAGAGTAATAATGTTTTTGGAGCCAGCAGCTACAAAGACACAATGAAAACAGAGACACACGAGACACGCCCACGCCCCCTCACGCACACTCGGTTGCATACACTCACACAATGAAC GACTCTTCAGCCCATTCACGTTGCTTTTGCACTATGTAAAAATTTTGTATAAAAAAAAACCCCAAACAACAAACCATGTAAACCATGTAATTTTCAAATGTTTCACTGTAAAATGTATAC ATACTTSATTTTGTAAATTTTTTTAAGTCGCAAGTAACTCATACATATTCTATTCTAAACCTCACGCATGTATTTATAATTTTATACACATTAGCTGGTGACCACCGATCGACGATCTG CATGGATGTTGGTCAGCTGGTGGCCAGCTAAAAGAACCTGTTAGCCAAGTAAGCCAAAAATGATAATAATTGGATTTTAAAACAATAACCATCAAAATAAACCAATTTTTTTCAA

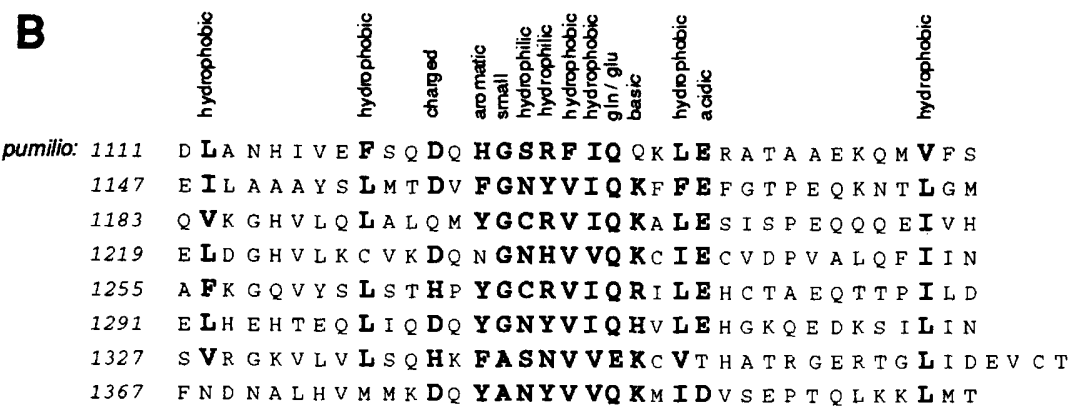

Figure 5. Sequence of pumilio. $(A)$ The composite cDNA nucleotide sequence was derived predominately from $\mathrm{cDNA}$ R7-1, which was isolated from a 4- to 8 - $\mathrm{hr}$ embryonic library. In addition, the $5^{\prime}$ sequences were obtained from clones isolated from a specifically primed library. Two different types of $5^{\prime}$ clones were isolated that differ in their $5^{\prime}$ exon, and the sequences of the longest clone of each type are shown. Primer extension analysis (data not shown) indicates that the sequences shown correspond approximately to the $5^{\prime}$ ends of these RNAs. The numbering of the nucleotide sequence is to the right of the sequence and is shown for the longest RNA form only. The position of the 12 introns that have been identified are indicated above the sequence $(\boldsymbol{\nabla})$. The predicted amino acid sequence of the Pumilio protein is indicated below the nucleotide sequence and is numbered to the left. Sixteen nucleotide differences were observed between the cDNA sequence, and the genomic sequence, two of which resulted in an altered amino acid. Two of these changes are the result of the insertion of a TA between positions 5853 and 5854 of the cDNA sequence. The remainder are listed as follows: [cDNA nucleotide and number, amino acid $\rightarrow$ genomic nucleotide (amino acid)] A $1279 \rightarrow$ G; T $2977 \rightarrow$ C; C 4353, Pro $\rightarrow$ G, Arg; C $5398 \rightarrow$ G; G $5401 \rightarrow$ A; A 5531, Ile $\rightarrow$ G, Val; G 5600, Gly $\rightarrow$ A, Ser; C $5880 \rightarrow$ A; A $5988 \rightarrow$ C; T $6055 \rightarrow$ A; T $6060 \rightarrow$ G; G $6177 \rightarrow$ T; T $6468 \rightarrow$ C; G $6728 \rightarrow$ A. (B) Contiguous portions of the Pumilio protein and the YGL023 protein have been aligned to reveal eight similar sequence motifs in each protein. In addition to the conserved chemical nature of amino acids distributed throughout the repeats, a number of specific amino acids are conserved in corresponding repeats. These include the conserved aspartic acid and histidine residues in the column under Pumilio amino acid 1122, the asparagine present in every other repeat under Pumilio amino acid 1126, and the conserved substitution of glutamic acid for glutamine only in the seventh repeat at Pumilio residue 1346 and Ygl023 residue 803. 
pumilio fusion gene (Fig. 6A) was inserted into the P-element vector pDM30, which contains the rosy ${ }^{+}$ marker gene, (Mismer and Rubin 1987) and was injected into embryos. Two of six transformant lines were ana-
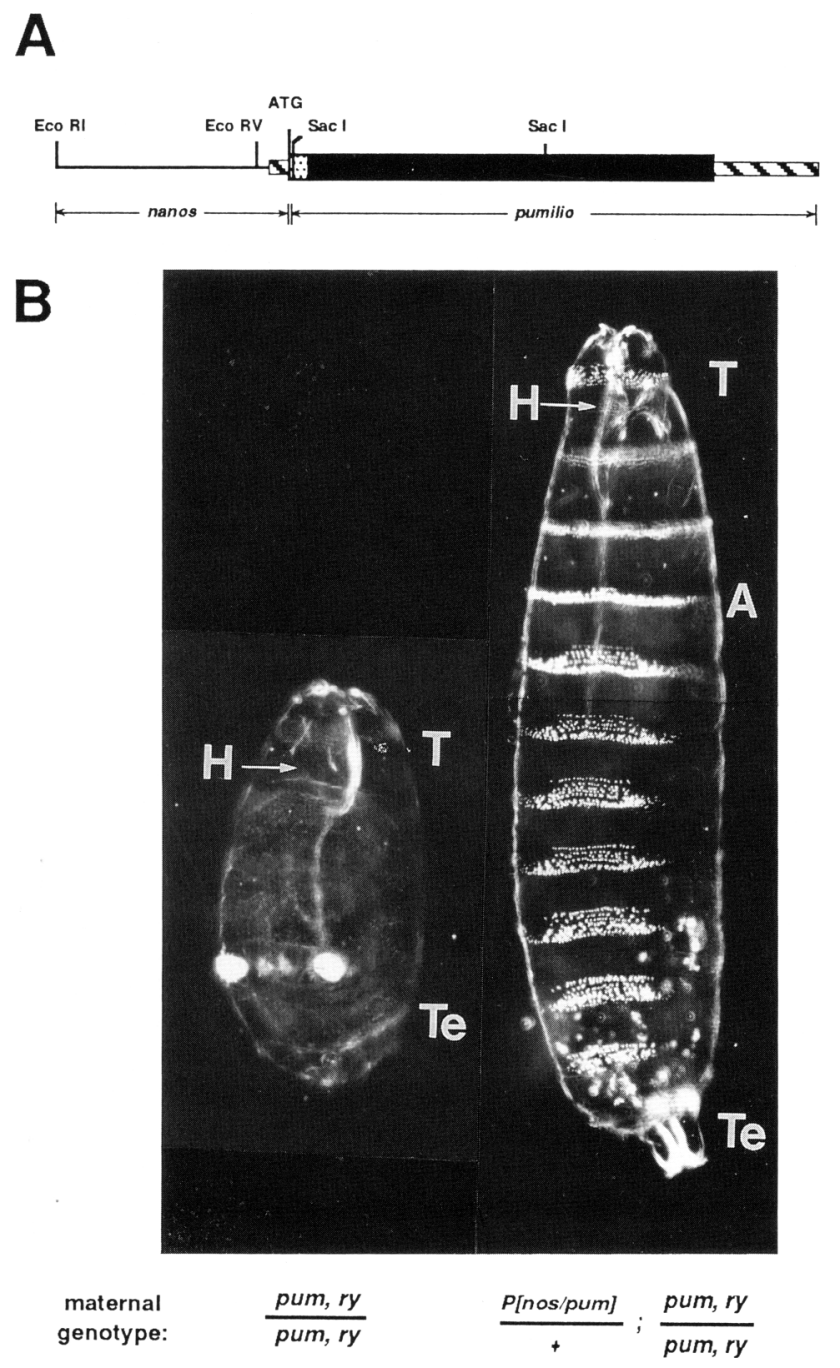

Figure 6. Rescue of the pumilio mutant phenotype. $(A)$ The nanos-pumilio fusion gene used to rescue the pumilio phenotype contains $5^{\prime}$-flanking sequences (thin line) and the $5^{\prime}$-untranslated region (hatched box) of nanos. Immediately after the nanos start codon, a SacI site was introduced and fused to a naturally occurring SacI site located 213 nucleotides upstream of and in-frame with the pumilio start codon. The resulting fusion gene encodes the entire Pumilio protein (solid box) with an additional 72 novel amino acids attached to its amino terminus (stippled box) followed by the pumilio $3^{\prime}$-untranslated region (hatched box). $(B)$ Cuticles are shown from a control embryo derived from pumilio, rosy homozygous females (left) and from an embryo derived from pumilio, rosy females that carry the nanos-pumilio fusion gene (right). Only the embryo from the transgenic females developed abdominal segments. $(H)$ head skeleton; $(T)$ thorax; the label marks the first of the three thoracic segments. (A) Abdomen; the label marks the first of the eight abdominal segments. (Te) Terminal structures with lightrefractile Filzkörper. Anterior is up. Dark-field optics were used. lyzed in detail by examining the larval cuticles of the progeny of homozygous pumilio females that carry the transgene. Transformation with this nanos-pumilio fusion gene results in complete rescue of the pumilio phenotype (Fig. 6B). Essentially all of the embryos produced by these transgenic females developed into viable larvae. Thus, we have identified the protein sequences necessary for pumilio function during oogenesis and early embryogenesis.

\section{pumilio RNA is localized to the posterior pole plasm}

The similar phenotype of pumilio and nanos mutants suggests an interaction between their gene products. Because the nanos mRNA is localized to the posterior pole of early embryos (Wang and Lehmann 1991), we analyzed the distribution of the pumilio RNA by in situ hybridization with the R7-1 cDNA to whole-mount embryos. We found that pumilio RNA is enriched at the posterior pole of early embryos (Fig. 7). In addition, uniform staining was consistently observed, suggesting that unlocalized pumilio RNA is also present throughout the embryo. We cannot detect pumilio RNA localization in embryos from females with rearrangements in the pumilio gene, which disrupt the pumilio transcription unit (Fig. 7).

To determine the genetic requirements for pumilio RNA localization, we analyzed a number of posterior group mutants. Embryos from females mutant for a strong allele of nanos or one of the EMS-induced pumilio alleles show normal localization of pumilio RNA (Fig. 7; data not shown), whereas embryos from females mutant for posterior group genes that affect the formation of the pole plasm, such as vasa, oskar, and staufen, fail to localize pumilio RNA (Fig. 7, data not shown) (Lehmann and Nüsslein-Volhard 1986; Schüpbach and Wieschaus 1986; Hay et al. 1988a,b; Lasko and Ashburnér 1988; Ephrussi et al. 1991; Kim-Ha et al. 1991; St. Johnston et al. 1991). Thus, as with nanos RNA localization, pumilio RNA localization depends on the formation of the pole plasm.

\section{Discussion}

We have identified the pumilio gene by mapping two chromosomal rearrangements that disrupt the gene and by complementation of the pumilio mutant phenotype using germ-line transformation with a minigene encoding the Pumilio protein. Analysis of mutations that disrupt the pumilio transcript demonstrates that pumilio is absolutely required for abdomen formation. We have investigated Pumilio function by measuring the effect of pumilio mutations on the expression of the Nanos protein and found that pumilio has no effect on either the level of expression or the distribution of nanos RNA or protein. We conclude that pumilio is an essential factor for abdomen formation and that it acts in conjunction with the localized abdominal determinant Nanos.

pumilio mutations result in the uniform translation of the maternal Hunchback protein (Fig. 1; Tautz et al. 


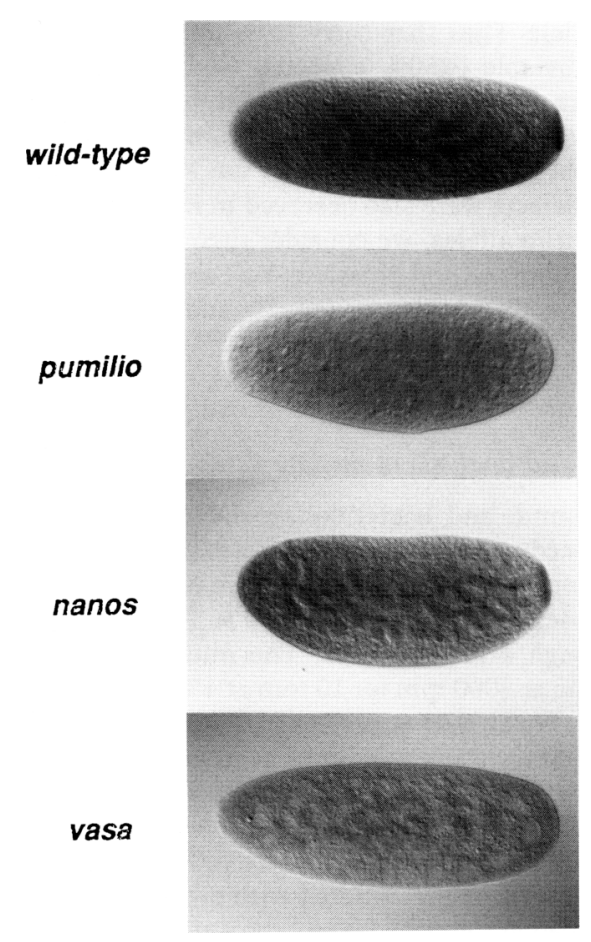

Figure 7. Posterior localization of pumilio RNA. Wholemount embryos were hybridized in situ to a digoxigenin-labeled pumilio cDNA fragment. Localization of pumilio RNA to the posterior pole plasm is observed in embryos derived from wild-type females (top panel). Embryos from females transheterozygous for $I n(3 R) M s C$ and $T(3 ; 1) F C 8$ show no RNA localization to the posterior pole (second panel), confirming that both rearrangements disrupt the pumilio transcript. pumilio RNA is localized as in wild type in embryos from homozygous nanos females (third panel) but not in embryos derived from homozy. gous vasa females (bottom panel). In addition, uniform staining is observed throughout the embryo with all genotypes tested. Because this is not seen without the use of a probe or when control probes are used, this suggests that pumilio RNA is also present throughout the embryo. The embryos shown are in nuclear cycle five to eight (Foe and Alberts 1983). Anterior is left and dorsal is up. Nomarski optics were used.

1987; Tautz 1988). The translational regulation of hunchback is also dependent on the function of nanos. Because we have now shown that pumilio has no effect on the expression or distribution of the Nanos protein, Pumilio is clearly not responsible for the transport of the Nanos protein, as had been suggested previously (Lehmann and Nüsslein-Volhard 1987). Rather, we suggest that Pumilio cooperates with the Nanos protein to repress hunchback translation in the posterior half of the embryo. However, these observations are also consistent with a model in which Pumilio represses hunchback translation in a manner completely independent of Nanos. We consider this latter possibility unlikely for a number of reasons. First, Pumilio and Nanos act on the same targets. Besides its effect on hunchback, Pumilio is also required for the repression of bicoid translation observed when the Nanos protein is ectopically expressed in the anterior of the embryo /Wharton and Struhl 1989; Lehmann and Nüsslein-Volhard 1991; L. Gavis and R. Lehmann, unpubl.). Second, the uniform distribution of Pumilio throughout the embryo (Macdonald 1992) is inconsistent with a direct role in establishing a concentration gradient of hunchback along the anterior-posterior axis. Finally, we cannot identify an independent activity for Pumilio. Although the localized nanos RNA present in pumilio mutant embryos is fully competent to rescue abdominal segmentation in posterior group mutants, no rescuing activity can be detected on transplantation of pumilio RNA present in nanos mutant embryos (Lehmann and Nüsslein-Volhard 1991) or in vitro-synthesized pumilio RNA (D. Barker and R. Lehmann, unpubl.). We find our data more consistent with a model in which Pumilio acts in conjunction with Nanos. Determining the role of Pumilio, therefore, will require an understanding of Nanos function.

How do Pumilio and Nanos cooperate and eventually control the repression of hunchback translation? Recent studies have identified a short RNA sequence present in the $3^{\prime}$-untranslated region of hunchback mRNA that is necessary and sufficient to confer Nanos-dependent translational repression (Wharton and Struhl 1991). However, it is presently unclear whether Nanos binds this sequence directly. A possible role for Pumilio could be to interact with hunchback mRNA, making the RNA more susceptible to translational repression. By interacting with hunchback mRNA, Pumilio might affect its secondary structure, a well-established mechanism of translational regulation (Altuvia et al. 1989). This might create an RNA structure or a Pumilio-RNA complex for which the Nanos protein has a higher affinity. Alternatively, the Pumilio protein may interact with the Nanos protein, enabling it to repress hunchback. Because we cannot order nanos and pumilio genetically, it is also formally possible that Nanos enables Pumilio to repress hunchback.

Little is known about mechanisms or molecules that control translation of specific mRNAs. Codependence of nanos and pumilio for translational repression could be achieved by a number of possible mechanisms, such as the introduction of a covalent protein modification or the formation of a protein-protein complex. Many of the pumilio alleles exhibit a cold-sensitive phenotype (Lehmann and Nüsslein-Volhard 1987). Cold sensitivity often indicates the assembly of large protein complexes, such as ribosomes (Guthrie et al. 1969; Tai et al. 1969; Moritz et al. 1991), bacteriophage capsids (Cox and Strack 1971; Jarvick and Botstein 1975), and microtubules (Schatz et al. 1988), owing to the inherent cold sensitivity of the hydrophobic interactions required for some of these associations (Correia and Williams 1983). Such a complex might involve an interaction between Pumilio and Nanos, between Pumilio and an unidentified protein, or among multiple Pumilio proteins. Finally, formation of a Nanos-Pumilio complex might be required for Nanos activity, possibly by increasing its affinity for hunchback mRNA.

Along with nanos and pumilio, at least eight other 
genes make up the posterior group. In addition to their abdominal phenotype, these eight genes are also required for the posterior localization of nanos and pumilio RNAs. These genes specifically affect nanos function, as the mutant phenotype of these posterior group genes can be rescued by transplantation of nanos RNA alone. Therefore, it has been proposed that the abdominal phenotype of these genes is the result of the lack of localized nanos activity (Wang and Lehmann 1991; Gavis and Lehmann 1992). pumilio function, on the other hand, seems unaffected in these mutants, which indicates that $\mathrm{pu}$ milio function does not require RNA localization. pumilio function is not limited to the posterior pole, as Pumilio acts in conjunction with Nanos even when Nanos is localized to the anterior pole of the embryo (E. Gavis and R. Lehmann, unpubl.). Thus, pumilio provides a factor required for abdomen formation that is present throughout the embryo, whereas nanos controls embryonic polarity through its posteriorly localized source.

Only one pumilio allele was identified in the initial mutagenesis screen for maternal effect genes on the third chromosome involved in embryonic patterning (Lehmann and Nüsslein-Volhard 1987). We have isolated many additional alleles on the basis of their failure to complement the pumilio maternal or zygotic (see below) phenotypes (Lehmann and Nüsslein-Volhard 1987, 1991; D. Barker, C. Detweiler, and R. Lehmann, unpubl.). Some of these alleles show reduced viability and the duplication of thoracic bristles of mutant adults. Thus, Pumilio has additional zygotic functions. Because pumilio does not share these phenotypes with nanos (Lehmann and Nüsslein-Volhard 1991; C. Wang, L. Dickinson, and R. Lehmann, unpubl.), it is likely that Pumilio interacts with additional gene products during later stages of development. Sequence analysis of the existing pumilio alleles, as well as a functional analysis of derivatives generated from the pumilio minigene, should help to define regions in the Pumilio protein specifically required for interaction with Nanos and other factors.

\section{Materials and methods}

\section{Nomenclature}

The mutant phenotypes described here depend strictly on the maternal genotype. Throughout the text, we refer to embryos derived from females mutant for a maternal effect gene, for example, pumilio or nanos, as mutant embryos irrespective of the genotype of the embryo.

\section{Mutant alleles and chromosomal rearrangements}

Two chromosomal rearrangements disrupt the pumilio transcription unit. In(3R)Msc has breakpoints in $84 \mathrm{~B}$ and $85 \mathrm{C} / \mathrm{D}$. The right breakpoint of $\operatorname{In}(3 R) M s c$ has been described to lie in $84 \mathrm{~F}$ (Lindsley and Zimm 1992) but more likely maps to $85 \mathrm{C}$, as published by Kemphues et al. (1983) and as supported by our cytogenetic, genetic, and molecular analysis (this paper, Lehmann 1985). T(3,1)FC8 is a translocation that transposes chromosomal material from the $84 \mathrm{D}$ to $85 \mathrm{C} / \mathrm{D}$ region to region 20 of the X chromosome. Both $\operatorname{In}(3 R) M s c$ and $T(3 ; 1) F C 8$ fail to complement the mutant pumilio phenotype when placed in trans to a pumilio allele. Flies that carry $\operatorname{In}(3 R) M s c$ and $T(3 ; 1) F C 8$ in trans are subviable $(<50 \%$ expected) and, in addition to the strong maternal phenotype, exhibit various morphological defects, such as small body size, aberrant wing posture, and additional bristles (most pronounced in the scutellar region). Because these defects were also observed in flies mutant for EMSinduced pumilio alleles, we consider them part of the pumilio phenotype (Lehmann and Nüsslein-Volhard 1987). The pumilio alleles used in this study are pum ${ }^{680}$ and pum ${ }^{E T 1}$, the nanos allele is nos ${ }^{L 7}$, and the vasa allele is $v^{D s^{D 1}}$ (as described in Lehmann and Nüsslein-Volhard 1987, 1991).

\section{Preparation and analysis of nucleic acids}

Plasmid, cosmid, and bacteriophage DNA were prepared by standard procedures (Sambrook et al. 1989). To prepare Drosophila genomic DNA, 50-100 adult flies were homogenized in $0.35 \mathrm{M}$ sucrose, $0.1 \mathrm{M}$ EDTA, and $0.05 \mathrm{M}$ Tris- $\mathrm{HCl}(\mathrm{pH} 8.0)$ and filtered through a Nitex screen. The nuclei were pelleted by centrifugation at $4000 \mathrm{rpm}$ for $10 \mathrm{~min}$ at $4^{\circ} \mathrm{C}$ and resuspended in $2 \mathrm{ml}$ of $0.1 \mathrm{M} \mathrm{NaCl}, 0.01 \mathrm{M}$ EDTA, $0.02 \mathrm{M}$ Tris- $\mathrm{HCl}(\mathrm{pH} 8.0)$ and $10 \mu \mathrm{g} / \mathrm{ml}$ of RNase, and incubated at room temperature for 15 min. Proteinase $\mathrm{K}$ and SDS were added to concentrations of 100 $\mu \mathrm{g} / \mathrm{ml}$ and $0.5 \%$, respectively, and the solution was incubated for $1 \mathrm{hr}$ at $65^{\circ} \mathrm{C}$. The DNA was extracted twice with phenolchloroform (1:1) and precipitated with ethanol. Southern blots were performed as described (Sambrook et al. 1989), except the DNA was transferred to Biotrans nylon membranes (ICN) with a Hoefer TransVac TE80.

Total Drosophila RNA was prepared by homogenizing $50-$ 100 adult flies in $3 \mathrm{ml}$ of $8 \mathrm{M}$ urea, $3 \mathrm{M} \mathrm{LiCl}, 0.005 \mathrm{M}$ dithiothreitol, and $0.005 \mathrm{M}$ EDTA for $1 \mathrm{~min}$ in a Brinkman polytron homogenizer at full speed. The homogenate was then centrifuged at $3000 \mathrm{rpm}$ for $10 \mathrm{~min}$ at $4^{\circ} \mathrm{C}$, and the clear supernatant transferred to a $15-\mathrm{ml}$ Corex tube and incubated at $0^{\circ} \mathrm{C}$ overnight. The RNA was pelleted by centrifugation at $12000 \mathrm{rpm}$ for $30 \mathrm{~min}$ in a Sorvall SS34 rotor at $4^{\circ} \mathrm{C}$ and resuspended in $0.01 \mathrm{M}$ Tris- $\mathrm{HCl}(\mathrm{pH} 7.0), 0.005 \mathrm{M}$ EDTA, and $0.5 \%$ SDS. This solution was extracted once with phenol-chloroform $(1: 1)$, and the RNA was precipitated with ethanol. Selection of polyadenylated RNA and RNA blots was performed as described (Sambrook et al. 1989), using formaldehyde agarose gels.

Sequencing of the pumilio cDNA R7-1 was performed with two nested sets of Tn9-induced deletions (Peng and Wu 1986), using Sequenase version 2.0 (U.S. Biochemical). Additional cDNA and genomic DNA were sequenced from doublestranded plasmid DNA using Sequenase version 2.0 or from cosmid DNA using the fmol sequencing system (Promega). Sequencing primers were synthesized with an Applied Biosystems 391 DNA synthesizer and deblocked oligonucleotides were precipitated with butanol (Sawadogo and Van Dyke 1991).

Compilation and initial analyses of DNA sequences were performed using the MacVector program (IBI). A DNA homology search was performed with the FASTA program using the GenBank, EMBL, and NBRF nucleic acid data bases (Pearson and Lipman 1988). Protein homology searches were performed with the TFASTA program using the above data bases and also with the BLAST network service of the National Center for Biotechnology Information using the PIR, SWISS-PROT, GenPept, and GPUpdate data bases (Altschul et al. 1990). The Pumilio, Ygl023 similarity was detected using a profile analysis (Gribskov et al. 1987).

Cloning of genomic and $c D N A$ sequences

Two libraries were constructed from fractions of BamHI-di- 
gested In(3R)Msc/ + DNA, purified by preparative agarose gel electrophoresis to include the two Msc breakpoint fragments $(7.8$ and $13.8 \mathrm{~kb}$ ), in the vector $\lambda \mathrm{L} 47.1$ and the Escherichia coli strain LE392 (Sambrook et al. 1989). Packaging was performed using the Packagene $\lambda$ DNA packaging system (Promega). The proximal breakpoint of the Msc inversion maps within the $A n$ tennapedia complex (Scott et al. 1983). A bacteriophage clone spanning this region was obtained (gift of $M$. Scott), and the breakpoint was mapped further to a $5.2-\mathrm{kb}$ BamHI restriction fragment within the $\mathrm{Scr}$ gene. This $5.2-\mathrm{kb} \mathrm{Scr}$ fragment was used to screen the Msc libraries. Fourteen positive clones ( $\lambda \mathrm{Msc}$-S) were identified from a total of 15,000 clones of the library containing the smaller Msc breakpoint $(7.8 \mathrm{~kb})$, whereas four positive clones $(\lambda \mathrm{Msc}-\mathrm{L}$ ) were identified from a total of 100,000 clones of the library containing the larger Msc breakpoint $(13.8 \mathrm{~kb})$. $\lambda \mathrm{Msc}-\mathrm{S}$ contained highly repetitive sequences in addition to the $S c r$ sequences, whereas $\lambda M s c-L$ contained only unique sequences that hybridized, as expected, to the position of the Antennapedia complex (84A), and pumilio (85CD) of the polytene chromosome. Wild-type cosmid and bacteriophage libraries were obtained from J. Tamkun (Tamkun et al. 1992) and initially screened with the pumilio sequences contained within $\lambda$ Msc-L using standard techniques (Sambrook et al. 1989). Additional screens were performed with cosmid insert end fragments and pumilio cDNA sequences.

A 4- to 8-hr Drosophila embryo cDNA library was provided by N. Brown (Brown and Kafatos 1988) in the form of purified plasmid DNA. This DNA was used to transform the $E$. coli strain DH5 $\alpha$ (BRL) both directly as well as after selection of clones $>5 \mathrm{~kb}$ by preparative agarose gel electrophoresis. Both platings of this library were screened with two genomic fragments from the pumilio region, a 7.3-kb EcoRI fragment covering the Msc breakpoint and a 6.8-kb PstI-BamHI fragment that maps $\sim 20 \mathrm{~kb}$ distal to the former. The Msc breakpoint probe identified 26 positive clones from a total of $\sim 400,000$ screened. Most of these also hybridized to the distal probe. The distal probe identified several hundred positive clones. Sequence analysis indicates that some of these are derived from the gene encoding the chromosomal protein D1 that had been mapped previously to this region (Ashley et al. 1989).

\section{Construction of a nanos-pumilio fusion gene and germ-line transformation}

A SacI restriction site was added to the nanos sequence immediately $3^{\prime}$ of the start codon by performing a polymerase chain reaction with a mutagenic oligonucleotide using the nanos genomic clone pCWl as a template (C. Wang, unpubl.). The amplified fragment extended from an EcoRV site 345 nucleotides upstream of the nanos transcriptional start through the start codon and ended with the introduced SacI site. This fragment was subcloned and then fused to upstream nanos sequences

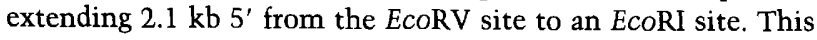
EcoRI-SacI fragment, containing the nanos promoter, $5^{\prime}$-untranslated leader region, and start codon, was then fused to the pumilio cDNA at a naturally occurring SacI site located 213 nucleotides $5^{\prime}$ of the pumilio start codon. This fusion gene, encoding the entire Pumilio protein with an additional 72 amino acids attached to its amino terminus, was inserted into the P-element vector pDM30 (Mismer and Rubin 1987) to generate $\mathrm{pDM} 30 /$ nos-pum. Germ-line transformation was performed as described previously (Spradling 1986) by injecting a solution containing $500 \mu \mathrm{g} / \mathrm{ml} \mathrm{pDM} 30 /$ nos-pum, $100 \mu \mathrm{g} / \mathrm{ml}$ $\mathrm{p} \pi 25.7 \mathrm{wc} \Delta 2-3$ (gift of D. Rio), $5 \mathrm{~mm} \mathrm{KCl}$, and $0.1 \mathrm{mM} \mathrm{NaPO}_{4}$ (pH 6.8) into embryos derived from a st pum ${ }^{680}$ ry ss/TM3 stock (mutations as described in Lindsley and Zimm 1992). Homozy- gous pum ${ }^{680} \mathrm{G}_{0}$ females were tested for fertility directly, whereas homozygous males and heterozygous animals were first backcrossed with the pum ${ }^{680}$ stock to generate pum ${ }^{680}$ homozygous females. Six transformant lines were identified and tested for complementation of the pumilio phenotype at $20^{\circ} \mathrm{C}$, the restrictive temperature for the maternal phenotype produced by the pum ${ }^{680}$ allele.

\section{Iniections into embryos}

Injections of cytoplasm and RNA were performed as described previously (Lehmann and Nüsslein-Volhard 1986; Wang and Lehmann 1991). Embryos were injected into the prospective abdominal region, between $20 \%$ and $50 \%$ egg length $10 \%=$ posterior pole). The developed cuticles were prepared as described (Lehmann and Nüsslein-Volhard 1991; Wang and Lehmann 1991) and scored for the number of abdominal segments formed. nanos RNA was synthesized in vitro from the full-length nanos cDNA clone pN5 as described in Wang and Lehmann (1991). Data from two independent experiments are summarized in Table 1 . In each experiment, freshly synthesized nanos transcript was injected in parallel into nanos and pumilio embryos. For transplantation of cytoplasm, posterior pole plasm was taken either from wild-type embryos or from embryos derived from females transheterozygous for $\operatorname{In}(3 R) M s c$ and $T(3 ; 1) F C 8$ and injected into the prospective abdominal region of embryos from females homozygous for nos ${ }^{L 7}$.

\section{Analysis of embryonic cuticles}

Cuticle preparations were performed essentially as described (Wieschaus and Nüsslein-Volhard 1986). To study the effect of temperature on mutant phenotypes, females mutant for a specific allele combination were kept at either $20^{\circ} \mathrm{C}$ or $29^{\circ} \mathrm{C}$. Embryos were collected for several hours and left to develop into larva for $48 \mathrm{hr}\left(20^{\circ} \mathrm{C}\right)$ or $12 \mathrm{hr}\left(29^{\circ} \mathrm{C}\right)$, and their cuticles were prepared. Embryos from females transheterozygous for In $(3 R) M s C$ and $T(3 ; 1) F C 8$ were collected at $20^{\circ} \mathrm{C}$ and at $29^{\circ} \mathrm{C}$. In each sample the cuticle patterns of 50 larvae were examined, and all larvae in both samples lacked abdominal segmentation. Embryos were dechorionated with $50 \%$ bleach, dissected from vitelline membranes with a glass pipette, and fixed in $50 \%$ Hoyer's mountant and $50 \%$ lactic acid overnight at $60^{\circ} \mathrm{C}$. Cuticles were photographed using dark field optics on a Zeiss Axiophot microscope with Kodak Technical Pan film.

\section{In situ hybridization to whole-mount embryos}

In situ hybridizations were performed as described by Tautz and Pfeifle (1989). For pumilio, the insert of the cDNA clone R7-1 was used as a probe, whereas the insert of the cDNA clone pN5 was used as a nanos probe (Wang and Lehmann 1991). Embryos were collected from wild type and pumilio $[\operatorname{In}(3 R) M s c /$ $T(3 ; 1) F C 8]$, nanos ( nos $^{L 7} /$ nos $\left.^{L 7}\right)$, and vasa $\left(\right.$ vas $^{D 1} /$ vas $\left.^{D 1}\right)$ mutant females for $2 \mathrm{hr}$ at $20^{\circ} \mathrm{C}$. These embryos were fixed and processed for whole-mount in situ hybridization of RNA.

\section{Antibody staining of whole-mount embryos}

To analyze the distribution of Hunchback and Nanos proteins in wild-type and mutant embryos, embryos were collected for 2 $\mathrm{hr}$ at $20^{\circ} \mathrm{C}$ or at room temperature and fixed immediately. Embryos were dechorionated, fixed, and devitellinized according to the method of Mitchison and Sedat (1983) and stored in methanol at $-20^{\circ} \mathrm{C}$. Because $\operatorname{In}(3 R) M s c / T(3 ; 1) F C 8$ flies lay very few eggs, embryos were alternatively devitellinized using fine tung- 
sten needles after fixation. Both devitellinization techniques resulted in identical antibody staining patterns. All incubations were performed in 1.5- $\mathrm{ml}$ polypropylene tubes with TBST $[0.05$ M Tris- $\mathrm{HCl}(\mathrm{pH} 7.0) 0.15 \mathrm{M} \mathrm{NaCl}$, and $0.01 \%$ Triton X-100] while agitating on an Adams nutator (Clay Adams). Embryos were rehydrated for $2 \mathrm{hr}$ at room temperature, and blocked by incubation in $1 \mathrm{ml}$ of $5 \%$ normal goat serum for $2 \mathrm{hr}$ at room temperature. Incubation in primary antibody was performed in $2 \%$ normal goat serum overnight at $4^{\circ} \mathrm{C}$. Embryos were washed with $1 \mathrm{ml}$, four times for $15 \mathrm{~min}$, and incubated with a biotinconjugated secondary antibody (goat) for $4 \mathrm{hr}$ at room temperature. Embryos were washed as described above and incubated with a horseradish peroxidase(HRP)-biotin/avidin complex (ABC Elite, Vector Labs) for $1 \mathrm{hr}$ at room temperature. Embryos were again washed as described above and incubated in 500 $\mu \mathrm{g} / \mathrm{ml}$ of diaminobenzidine tetrachloride (DAB), $0.006 \% \mathrm{H}_{2} \mathrm{O}_{2}$ to develop color. Embryos were photographed using Nomarski optics on a Zeiss Axiophot microscope with Kodak Technical Pan film or Kodak Ektachrome 64 film.

To measure the distribution of the Nanos protein, we used a modification of the filtered fluorescence imaging technique (Karr and Kornberg 1989). This technique exploits the ability of the $3,3^{\prime}$-diaminobenzidine precipitate produced by HRP to reduce the intensity of a fluorescent signal by absorbing the incident and/or emitted light. In our modification of this technique, cleavage-stage embryos were HRP-labeled with a rabbit polyclonal antiserum directed against the Nanos protein as described above and then incubated with an antiserum directed against yeast glucose-6-phosphate dehydrogenase /Sigma Chemical) for $2 \mathrm{hr}$ at room temperature. The embryos were then washed as described above and incubated with a fluorescein isothiocyanate-conjugated secondary antibody for $2 \mathrm{hr}$ at room temperature, washed again, and mounted in TBST, $70 \%$ glycerol. Embryos were visualized with epifluorescence optics on a Zeiss Axiophot microscope. Video images were collected with a Hamamatsu C2400 Newvicon camera and an Argus 10 image processor (Hamamatsu). These images were then digitized using a Bio-Rad MRC 600 confocal microscope workstation and quantitatively analyzed on a Macintosh with NIH Image (version 1.41). Fluorescence intensity profiles along the length of several wild-type and pumilio embryos were averaged and inverted to represent the distribution of the Nanos protein in graphic form (Fig. 3). Statistical comparisons were performed at several positions along the length of the embryos using the Wilcoxon rank sum test (Lindgren et al. 1978). No significant difference was found between wild-type and pumilio embryos, whereas there is $>99.5 \%$ probability that the distribution of the Nanos protein is statistically different in embryos derived from females carrying one copy of the nanos gene [Df $\left.(3 R) ; D I^{F X 1} / T M 3\right]$ or four copies [ $\mathrm{P}\left[\right.$ gnos] $/ \mathrm{P}\left[\right.$ gnos]). $\mathrm{P}[$ gnos $]$ is a rosy ${ }^{+}$-marked $\mathrm{P}$-element containing the entire nanos gene (Wang and Lehmann 1991).

\section{Antibody production}

The anti-Nanos antibody is a rabbit polyclonal serum raised against a Nanos fusion protein produced in bacteria. Briefly, a PstI-BgIII fragment of the nanos cDNA pN5 (Wang and Lehmann 1991) was subcloned into the expression vector pET-3c (Rosenberg et al. 1987) to produce a fusion protein encoding 11 amino acids of $\mathrm{T} 7$ gene 10 protein fused in-frame to amino acids $51-400$ of the 400-amino-acid nanos open reading frame. The fusion protein was injected into rabbits as inclusion bodies us. ing Freund's adjuvant.

The specificity of the antibody is shown by staining embryos derived from females homozygous for the nanos ${ }^{B N}$ allele (data not shown); homozygous nanos ${ }^{B N}$ females do not contain de- tectable levels of nanos RNA (C. Wang and R. Lehmann, unpubl.). Embryos derived from these females show a uniform level of staining comparable to the level at the anterior half of wild-type embryos stained in parallel. Therefore, we concluded that the staining seen in the posterior half of wild-type embryos is specific for Nanos. The background, nonspecific staining can be reduced, while preserving the specific staining, by repeatedly preabsorbing the serum against wild-type, pregastrula embryos (data not shown).

\section{Acknowledgments}

We thank Daniel St. Johnston for bringing the Pumilio, Ygl023 similarity to our attention, Corrie Detweiler for assistance in the isolation of pumilio alleles and genomic clones, Nick Brown for the cDNA library, John Tamkun for the genomic libraries, Diethard Tautz for the Hunchback antibody, and Will Gilbert for help with data base searches. We are also grateful to Don Rio and the members of the Lehmann laboratory for helpful discussions, Dan Curtis and Susan Whoriskey for comments on the manuscript, and Aji Kron for help in preparation of the manuscript. This work was supported by grants from the Whitaker Health Sciences Fund, the Howard Hughes Medical Institute, and a Packard fellowship to R.L., and by a postdoctoral fellowship from the National Institute of Child Health and Human Development to D.B. R.L. is a Howard Hughes Medical Institute assistant investigator.

The publication costs of this article were defrayed in part by payment of page charges. This article must therefore be hereby marked "advertisement" in accordance with 18 USC section 1734 solely to indicate this fact.

\section{References}

Altschul, S.F., W. Gish, W. Miller, E.W. Myers, and D.J. Lipman. 1990. Basic local alignment search tool. I. Mol. Biol. 215: 403-410.

Altuvia, S., D. Kornitzer, D. Teff, and A.B. Oppenheim. 1989. Alternative mRNA structures of the cIII gene of bacteriophage lambda determine the rate of its translation initiation. J. Mol. Biol. 210: 265-280.

Ashley, C.T., C.G. Pendleton, W.W. Jennings, A. Saxena, and C.V.C. Glover. 1989. Isolation and sequencing of cDNA clones encoding Drosophila chromosomal protein D1. I. Biol. Chem. 264: 8394-8401.

Berleth, T., M. Burri, G. Thoma, D. Bopp, S. Richstein, G. Frigerio, M. Noll, and C. Nüsslein-Volhard. 1988. The role of localization of bicoid RNA in organizing the anterior pattern of the Drosophila embryo. EMBO I. 7: 1749-1756.

Boswell, R.E. and A.P. Mahowald. 1985. tudor, a gene required for assembly of the germ plasm in Drosophila melanogaster. Cell 43: 97-104.

Boswell, R.E., M.E. Prout, and J.C. Steichen. 1991. Mutations in a newly identified Drosophila melanogaster gene, mago nashi, disrupt germ cell formation of mirror-image symmetrical double abdomen embryos. Development 113: 373-384.

Brown, N.H. and F.C. Kafatos. 1988. Functional cDNA libraries from Drosophila embryos. J. Mol. Biol. 203: 425-437.

Chen, W., E. Balzi, E. Capieaux, and A. Goffeau. 1991. The YGL023 gene encodes a putative regulatory protein. Yeast 7: 309-312.

Correia, J.J. and R.C.J. Williams. 1983. Mechanisms of assembly and disassembly of microtubules. Annu. Rev. Biophys. Bioeng. 12: 211-235.

Cox, J.H. and H.B. Strack. 1971. Cold-sensitive mutants of bac- 
teriophage lambda. Genetics 67: 5-17.

Ephrussi, A., L.K. Dickinson, and R. Lehmann. 1991. oskar organizes the germ plasm and directs localization of the posterior determinant Nanos. Cell 66: 37-50.

Foe, V.E. and B.M. Alberts. 1983. Studies of nuclear and cytoplasmic behavior during the five mitotic cycles that precede gastrulation in Drosophila embryos. J. Cell. Sci. 61:31-70.

Frigerio, D., M. Burri, D. Bopp, S. Baumgartner, and M. Noll. 1986. Structure of the segmentation gene paired and the Drosophila PRD gene set as part of a gene network. Cell 47: 735-746.

Gavis, E.R. and R. Lehmann. 1992. Localization of nanos RNA controls embryonic polarity. Cell 71: 301-313.

Gribskov, M., A.D. McLachlan, and D. Eisenberg. 1987. Profile analysis: Detection of distantly related proteins. Proc. Natl. Acad. Sci. 84: 4355-4358.

Guthrie, C., H. Nashimoto, and M. Nomura. 1969. Structure and function of $E$. coli ribosomes. VIII. Cold-sensitive mutants defective in ribosome assembly. Proc. Nat1. Acad. Sci. 63: 384-391.

Hay, B., L. Ackerman, S. Barbel, L.Y. Jan, and Y.N. Jan. 1988a. Identification of a component of Drosophila polar granules. Development 103: 625-640.

Hay, B., L.Y. Jan, and Y.N. Jan. 1988b. A protein component of Drosophila polar granules is encoded by vasa and has extensive sequence similarity to ATP-dependent helicases. Cell 55: 577-587.

Hülskamp, M., C. Schröder, C. Pfeifle, H. Jäckle, and D. Tautz. 1989. Posterior segmentation of the Drosophila embryo in the absence of a maternal posterior organizer gene. Nature 338: 629-632.

Hülskamp, M., C. Pfeifle, and D. Tautz. 1990. A morphogenetic gradient of hunchback protein organizes the expression of the gap genes Krüppel and knirps in the early Drosophila embryo. Nature 346: 577-580.

Irish, V., R. Lehmann, and M. Akam. 1989. The Drosophila posterior-group gene nanos functions by repressing hunchback activity. Nature 338: 646-648.

Jarvick, J. and D. Botstein. 1975. Conditional-lethal mutations that suppress genetic defects in morphogenesis by altering structural proteins. Proc. Natl. Acad. Sci. 72: 2738-2742.

Karr, T.L. and T.B. Kornberg. 1989. fushi tarazu protein expression in the cellular blastoderm of Drosophila detected using a novel imaging technique. Development 105: 95-103.

Kemphues, K.J., E.C. Raff, and T.C. Kaufman. 1983. Genetic analysis of $B-2 t$, the structural gene for the testis specific $\beta$-tubulin subunit in Drosophila melanogaster. Genetics 105: 345-356.

Kim-Ha, J., J.L. Smith, and P.M. Macdonald. 1991. oskar mRNA is localized to the posterior pole of the Drosophila oocyte. Cell 66: 23-35.

Lasko, P.F. and M. Ashburner. 1988. The product of the Drosophila gene vasa is very similar to eukaryotic initiation factor-4A. Nature 335: 611-617.

Lehmann, R. 1985. "Regionsspezifische Segmentierungsmutanten bei Drosophila melanogaster Meigen." Ph.D. Thesis. Universität Tübingen, Tübingen, Germany.

Lehmann, R. and C. Nüsslein-Volhard. 1986. Abdominal segmentation, pole cell formation, and embryonic polarity require the localized activity of oskar, a maternal gene in Drosophila. Cell 47: 141-152.

- 1987. Involvement of the pumilio gene in the transport of an abdominal signal in the Drosophila embryo. Nature 329: $167-170$.

- 1991. The maternal gene nanos has a central role in pattern formation of the Drosophila embryo. Development
112: 679-691

Lindgren, B.W., G.W. McElrath, and D.A. Berry. 1978. Introduction to probability and statistics. Macmillan, New York.

Lindsley, D.L. and G.G. Zimm. 1992. The genome of Drosophila melanogaster. Academic Press, Inc., San Diego.

Macdonald, P.M. 1992. The Drosophila pumilio gene: An unusually long transcription unit and an unusual protein. Development 114: 221-232.

Manseau, L.J. and T. Schüpbach. 1989. cappuccino and spire: Two unique maternal-effect loci required for both the anteroposterior and dorsoventral patterns of the Drosophila embryo. Genes \& Dev. 3: 1437-1452.

Mismer, D. and G.M. Rubin. 1987. Analysis of the promoter of the ninaE opsin gene in Drosophila melanogaster. Genetics 116: $565-578$.

Mitchison, T.J. and J. Sedat. 1983. Localization of antigenic determinants in whole Drosophila embryos. Dev. Biol. 99: 261-264.

Moritz, M., B.A. Pulaski, and J.L.J. Woolford. 1991. Assembly of $60 \mathrm{~S}$ ribosomal subunits is perturbed in temperature-sensitive yeast mutants defective in ribosomal protein L16. Mol. Cell Biol. 11: 5681-5692.

Nüsslein-Volhard, C. 1991. Determination of the embryonic axis of Drosophila. Development (Suppl) 1: 1-10.

Nüsslein-Volhard, C., H.G. Frohnhöfer, and R. Lehmann. 1987. Determination of anteroposterior polarity in Drosophila. Science 238: 1675-1681.

Pearson, W.R. and D.J. Lipman. 1988. Improved tools for biological sequence comparison. Proc. Natl. Acad. Sci. 85: 2444-2448.

Peng, Z. and R. Wu. 1986. A simple and rapid nucleotide sequencing strategy and its application in analyzing a rice histone 3 gene. Gene 45: 247-252.

Perrimon, N., D. Mohler, L. Engstrom, and A.P. Mahowald. 1986. X-linked female-sterile loci in Drosophila melanogaster. Genetics 113: 695-712.

Perrimon, N., L. Engstron, and A.P. Mahowald. 1989. Zygotic lethals with specific maternal effect phenotypes in Drosophila melanogaster. I. Loci on the X Chromosome. Genetics 121: 333-352.

Rosenberg, A.H., B.N. Lade, D. Chui, W. Lin, J.J. Dunn, and F.W. Studier. 1987. Vectors for selective expression of cloned DNAs by T7 RNA polymerase. Gene 56: 125-135.

St. Johnston, D. and C. Nüsslein-Volhard. 1992. The origin of pattern and polarity in the Drosophila embryo. Cell 68: 201219.

St. Johnston, D., W. Driever, T. Berleth, S. Richstein, and C. Nüsslein-Volhard. 1989. Multiple steps in the localization of bicoid RNA to the anterior pole of the Drosophila oocyte. Development (Suppl.) 107: 13-19.

St. Johnston, D., D. Beuchle, and C. Nüsslein-Volhard. 1991. staufen, a gene required to localize maternal RNAs in the Drosophila egg. Cell 66: 51-63.

Sambrook, J., E.F. Fritsch, and T. Maniatis. 1989. Molecular cloning: A laboratory manual. Cold Spring Harbor Laboratory Press, Cold Spring Harbor, New York.

Sawadogo, M. and M.W. Van Dyke. 1991. A rapid method for the purification of deprotected oligodeoxynucleotides. $\mathrm{Nu}$ cleic Acids Res. 19: 674.

Schatz, P.J., F. Solomon, and D. Botstein. 1988. Isolation and characterization of conditional-lethal mutations in the TUB1 a-tubulin gene of the yeast Saccharomyces cerevisiae. Genetics 120: 681-695.

Schröder, C., D. Tautz, E. Seifert, and H. Jäckle. 1988. Differential regulation of the two transcripts from the Drosophila gap segmentation gene hunchback. EMBO f. 7: 2881-2887. 
Barker et al.

Schüpbach, T. and E. Wieschaus. 1986. Maternal-effect mutations altering the anterior-posterior pattern of the Drosophila embryo. Wilhelm Roux's Arch. Dev. Biol. 195: 302317.

1989. Female sterile mutations on the second chromosome of Drosophila melanogaster. I. Maternal effect mutations. Genetics 121: 101-117.

Scott, M.P., A.J. Weiner, T.I. Hazelrigg, B.A. Polisky, V. Pirrotta, F. Scalenghe, and T.C. Kaufman. 1983. The molecular organization of the Antennapedia locus of Drosophila. Cell 35: 763-776.

Spradling, A.C. 1986. P element-mediated transformation. In Drosophila: A practical approach (ed. D.B. Roberts) pp.175198. IRL Press, Oxford, England.

Struhl, G. 1989. Differing strategies for organizing anterior and posterior body pattern in Drosophila embryos. Nature 338: 741-744.

Struhl, G., P. Johnston, and P.A. Lawrence. 1992. Control of Drosophila body pattern by the hunchback morphogen gradient. Cell 69: 237-249.

Tai, P., D.P. Kessler, and J. Ingraham. 1969. Cold-sensitive mutations in Salmonella typhimurium which affect ribosome synthesis. I. Bacteriol. 97: 1298-1304.

Tamkun, J.W., R. Deuring, M.P. Scott, M. Kissinger, A.M. Pattattucci, T.C. Kaufman, and J. A. Kennison. 1992. brahma: A regulator of Drosophila homeotic genes structurally related to the yeast transcriptional activator SNF2/SW12. Cell 68: $561-572$.

Tautz, D. 1988. Regulation of the Drosophila segmentation gene hunchback by two maternal morphogenetic centres. Nature 332: 281-284.

Tautz, D. and C. Pfeifle. 1989. A non-radioactive in situ hybridization method for the localization of specific RNAs in Drosophila embryos reveals translational control of the segmentation gene hunchback. Chromosoma 98: 81-85.

Tautz, D., R. Lehmann, H. Schnurch, R. Schuh, E. Seifert, A. Kienlin, K. Jones, and $H$. Jäckle. 1987. Finger protein of novel structure encoded by hunchback, a second member of the gap class of Drosophila segmentation genes. Nature 327: 383-389.

Wang, C. and R. Lehmann. 1991. Nanos is the localized posterior determinant in Drosophila. Cell 66: 637-648.

Wharton, R.P. and G. Struhl. 1989. Structure of the Drosophila bicaudal $\mathrm{D}$ protein and its role in localizing the posterior determinant nanos. Cell 59: 881-892.

- 1991. RNA regulatory elements mediate control of Drosophila body pattern by the posterior morphogen nanos. Cell 67: 955-967.

Wieschaus, E.F. and C. Nüsslein-Volhard. 1986. Looking at embryos. In Drosophila: A practical approach led. D.B. Roberts), pp. 199-227. IRL Press, Washington, D.C. 


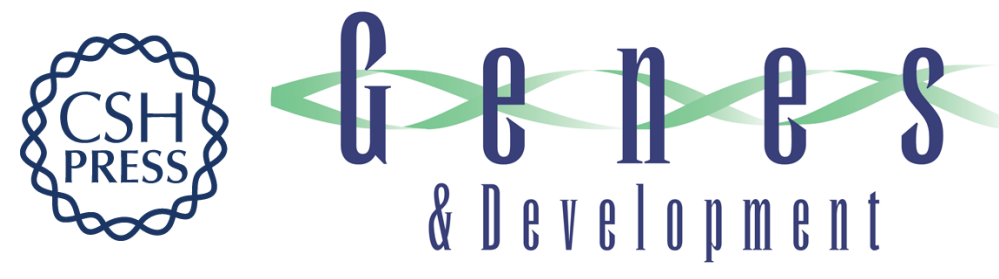

\section{Pumilio is essential for function but not for distribution of the Drosophila abdominal determinant Nanos.}

D D Barker, C Wang, J Moore, et al.

Genes Dev. 1992, 6:

Access the most recent version at doi:10.1101/gad.6.12a.2312

References This article cites 60 articles, 22 of which can be accessed free at:

http://genesdev.cshlp.org/content/6/12a/2312.full.html\#ref-list-1

License

Email Alerting

Service

Receive free email alerts when new articles cite this article - sign up in the box at the top right corner of the article or click here.

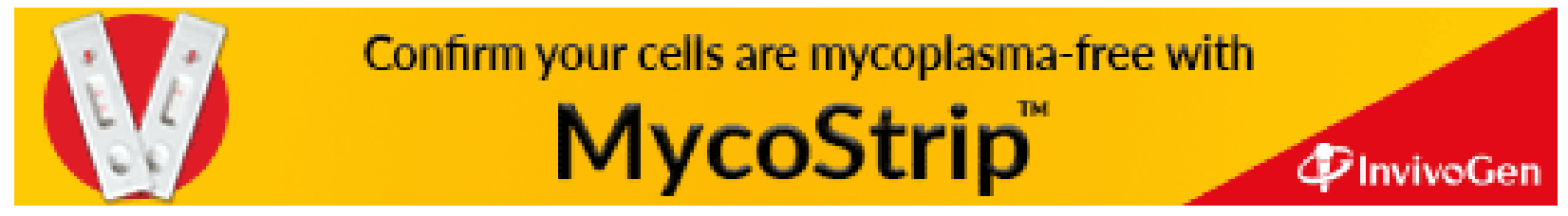

